DEPARTMENT OF ECONOMICS WORKING PAPER SERIES

The distributive cycle: Evidence and current debates

\author{
Jose Barrales-Ruiz \\ Ivan Mendieta-Muñoz \\ Codrina Rada \\ Daniele Tavani \\ Rudiger von Arnim
}

Working Paper No: 2020-07

April 2021

\author{
University of Utah \\ Department of Economics \\ 260 S. Central Campus Dr., GC. 4100 \\ Tel: (801) 581-7481 \\ Fax: (801) 585-5649 \\ http://www.econ.utah.edu
}




\title{
The distributive cycle: Evidence and current debates
}

\author{
Jose Barrales-Ruiz \\ Department of Economics, Universidad Católica de la Santísima Concepción \\ jbarrales@ucsc.cl
}

Ivan Mendieta-Muñoz

Department of Economics, University of Utah

ivan.mendietamunoz@utah.edu

Codrina Rada

Department of Economics, University of Utah $\underline{\text { rada@economics.utah.edu }}$

\author{
Daniele Tavani \\ Department of Economics, Colorado State University \\ Daniele.Tavani@colostate.edu \\ Rudiger von Arnim \\ Department of Economics, University of Utah \\ rudiger.vonarnim@economics.utah.edu
}

\begin{abstract}
This paper surveys current debates on the distributive cycle. The literature builds on R.M. Goodwinš seminal 1967 chapter titled 'A growth cycle.'We review theoretical motivations for the distributive cycle, which, despite signif-icant differences, all imply that macroeconomic activity leads the labor share in a counter-clockwise cycle in the activity-labor share plane. Subsequently, we summarize and update evidence on the existence of a distributive cycle, with a focus on the post-war US macroeconomy. We analyze activity and labor share series and their interaction in the frequency domain, and also employ stan-dard vector autoregressions. Results confirm the distributive cycle for the US post-war period. We contextualize results vis-à-vis current debates: (1) we consider a financial cycle, to rebut the theoretical possibility of pseudo-Goodwin" cycles, (2) demonstrate that a suppressed labor share and stagnation are com-patible with short run Goodwin cycles, and argue that this link presents the way forward for research on secular stagnation.
\end{abstract}

Keywords: Distributive cycle; US labor share of income; neo-Goodwin.

JEL Classification: E12; E24; E25; E32. 


\section{Introduction}

The theory of the distributive cycle posits that economic growth is the result of conflictual and cyclical interaction between profit-seeking capital and the workers employed on its behalf. The cycle implies that a measure of macroeconomic activity (employment rate, rate of utilization, or output gap) leads a measure of the labor share to generate a counter-clockwise cycle in the activity-labor share plane. The purpose of this review is to argue (i) that motivation for a distributive cycle can be found in different literatures, and (ii) that empirical evidence for a distributive cycle in the US post-war macroeconomy is strong - even in the more recent period which saw a dramatic decline in the labor share. Further, (iii) the distributive cycle is robust to the inclusion of financial variables. Last, but by no means least, we argue that (iv) the theory of the distributive cycle, augmented with induced or endogenous labor productivity growth, provides a useful framework for the discussion of inequality- and austerity-driven secular stagnation. In particular, we assert that while the evidence for short run "profit led" activity is exceedingly strong, the long run may become "wage led" through the channel of induced technical change, or endogenous labor-augmenting technical change. In our view, recognition of the facts regarding the short run opens the door to much needed further research on secular stagnation.

The remainder of this survey is organized as follows. ${ }^{1}$ Section 2 summarizes theoretical motivations for the distributive cycle. The key argument is that a distributive (business) cycle cum growth can be motivated on the basis of classical, postKeynesian and old-Keynesian (or neoclassical synthesis) ideas. Section 3 presents data series for macroeconomic activity and the labor share. Our focus lies on the US, post-world war II. We utilize the employment rate (proxied as the remainder to one from the civilian unemployment rate) and the output gap (as the log ratio of real GDP and the Congressional Budget Office's estimate of real potential GDP). Numerous measurement problems arise, especially for the labor share. We compare in this section six different measures. As has become more common in the recent literature, we describe the series in time and frequency domain. Results indicate that activity and labor share measures feature very similar short-to-medium run dynamics. In particular, a frequency peak is observed at about ten years. The wavelet power spectrum confirms this, albeit frequency peaks appear to be time varying. In contrast, the longer run trends of the labor share measures differ significantly.

Section 4 provides evidence in support of the existence of a distributive cycle in the post-war US macroeconomy. First, we survey key results from the literature. Second, we selectively reproduce and update certain applications. Two methodolo-

\footnotetext{
${ }^{1}$ While not much in this paper is very strictly speaking new, we reproduce and update key results and offer new contextualization, and in this manner hopefully advance the literature. Section 4.2 is an exception, as it presents a new methodology in this literature: the calculation of the phase difference for a specific frequency band between two time series.
} 
gies are put forth: wavelet coherence and vector autoregressions (VAR). The former presents a covariance decomposition in time and frequency domain for the two state variables, and we illustrate the relationship for selected activity and labor share measures. The frequency peak found for univariate series in the previous section shows up here, too: the coherence tends to be strong at these short-to-medium run frequencies. Moreover, calculation of the phase difference in frequency domain provides strong evidence for the counter-clockwise "Goodwin pattern" in activity-labor share plane in the 4-16 year frequency band. For brevity's sake, and justified by the similar (business cycle frequency) characteristics of the series, we report VAR results for output gap and employment rate vis-à-vis one labor share measure. Results across the literature and presented here provide robust support for a US post-war distributive cycle - although new questions continue to arise.

Section 5 therefore contextualizes the distributive cycle vis-à-vis two topics: a financial cycle, and secular stagnation. The former has recently been cast as a challenge to the distributive cycle; we discuss the arguments and show it to be questionable both theoretically and empirically. Specifically, the distributive cycle with "profit squeeze" distribution and "profit led" macroeconomic activity is robust to the inclusion of a financial variable in a standard VAR. The latter topic-secular stagnation - is in our view central to finding consensus in the literature and advancing a coherent research agenda: while the distributive cycle rules at business cycle frequency, it evolves around a steady state in which long run macroeconomic performance is associated positively with the labor share and also distributive and demand policy variables. Section 6 concludes, largely by circumscribing further relevant areas of current research we are not able to cover here.

\section{Theory}

This section provides an overview of theoretical motivations put forth for a distributive cycle, or, equivalently, the classical growth cycle. The original impetus was given by Marx in Capital, vol. 1, published in 1867, and formulated-famously, succinctly, and true to its classical roots-by Goodwin (1967). It is widely recognized that Goodwin's contribution is as essential to classical and post-Keynesian approaches to growth as Solow's theory to neoclassical approaches to growth (Flaschel, 2015, p. 1591$)^{2}$

In the original contribution, labor and capital play the role of predator and prey in a biological model of species competition (see Lotka, 1925; Volterra, 1931). They are in conflict, but exist symbiotically: the rate of accumulation is a function of the rate of profit; with a given output-capital ratio, the rate of profit falls with labor's ability to force sharing of gains in a tightening labor market. Hence, labor's success implies the

\footnotetext{
${ }^{2}$ See Akerlof and Stiglitz (1968) for an early discussion that relates Goodwin's setup to an environment with malleable capital.
} 
end of the expansion, and its failure the seeds for recovery. Here we provide a brief exposition of the original model, and subsequently discuss extensions and variants in the more recent literature. This review is not intended to be comprehensive, but rather emphasize the issue of central importance for subsequent empirical discussion: all model variants, despite their significant theoretical differences, predict a counterclockwise movement in activity-labor share space, or, equivalently, that the activity variable leads the labor share.

Textbook representations of Goodwin's original model abound; for important examples, see Lorenz (1993, chap. 2) and Gandolfo (2010, chap. 23). In the following brief summary, $\hat{x}=\dot{x} / x$ is the proportional growth rate of variable $x$, or its time rate of change relative to its level. We use the following notation: $e \equiv L / N$ is the rate of employment, and $\sigma \equiv Y^{*} / K$ is the ratio of full capacity-output to capital; $\psi \equiv \omega / A$ is the labor share, with $\omega \equiv w / P$ and $A \equiv Y / L$ real wage and average labor productivity, respectively. $\pi \equiv 1-\psi$ follows as the share of profits, and $r \equiv \pi \sigma$ as the rate of profit. It is assumed that all profits are saved and reinvested, and all wages are consumed; $s_{\pi}=1 ; s_{\psi}=0$. Leontief production implies that $\hat{K}=\hat{Y}$, and (weak, or classical) Say's Law implies $\dot{K}=I=S$. Labor productivity and labor force grow at exogenous rates, and in sum define a natural rate of growth $g^{*}=a+n$. Last but not least, a linear real wage Phillips curve determines the rate of change in the numerator of the labor share, with the employment rate as the single right-hand-side variable:

$$
\hat{\omega}=-\omega_{0}+\rho e,
$$

where $\omega_{0}, \rho$ are positive constants. ${ }^{3}$

The state variables of the two-dimensional model are employment rate and the labor share, and the differential equations can be derived through log-differentiation:

$$
\begin{aligned}
\dot{e} & =e((1-\psi) \sigma-(a+n)) \\
\dot{\psi} & =\psi\left(\rho e-\left(\omega_{0}+a\right)\right) .
\end{aligned}
$$

This seemingly innocuous setup and list of assumptions imply the following standard observations and results: (i) the rate of accumulation is constrained by the rate of profits, which depends positively (and only, since $\sigma$ is constant) on the functional distribution of income; but (ii) in steady state, the rate of profit is equal to the rate of accumulation and the natural rate of growth; ${ }^{4}$ (iii) the rate of real wage growth is constrained by the employment rate; but (iv) in steady state, the rate of real wage growth is equal to the rate of labor productivity growth, which implies that (v) the

\footnotetext{
${ }^{3}$ Desai et al. (2006) shows that linearity of the Phillips curve can lead to employment rate and labor share exceeding unity. A non-linear real wage Phillips curve rectifies this problem.

${ }^{4}$ The equality arises since $s_{\pi}=1$ in the original. If capitalists save, accumulation and the labor share increase in the savings rate. See Zamparelli (2015, p. 254) for discussion.
} 
labor share is constant (and all of Kaldor's stylized facts are satisfied); and (vi) the solution to the system above implies a counter-clockwise and conservative oscillation in $e, \psi$ space. ${ }^{5}$ Moreover, (vii) a strengthening of worker's bargaining power via the Phillips Curve parameters implies a lower steady state employment rate and no effect on the labor share, whereas (viii) a rise in the exogenous growth rate of labor productivity increases the steady state rates of employment and accumulation and decreases the labor share. These last two points emphasize that employment and pay for it are only appendages, albeit necessary, of accumulation, which in turn occurs only when surplus is available.

Indeed, the two all-important aspects of the distributive cycle are the combination of profit-seeking capitalist accumulation and the reserve army mechanism. The former reigns supreme in all the writings of the classics, the latter can be highlighted in the following quote:

"II]f a surplus labouring population is a necessary product of accumulation or of the development of wealth on a capitalist basis, this surplus population becomes [...] a condition of existence of the capitalist mode of production. It forms a disposable industrial reserve army, that belongs to capital quite as absolutely as if the latter had bred it at its own cost. Independently of the limits of the actual increase of population, it creates, for the changing needs of the self-expansion of capital, a mass of human material always ready for exploitation. [... T]here must be the possibility of throwing great masses of men suddenly on the decisive points without injury to the scale of production in other spheres. [...] The industrial reserve army, during the periods of stagnation and average prosperity, weighs down the active labour-army; during the periods of over-production and paroxysm, it holds its pretensions in check.

(Marx, Capital, Vol.1, Chapter 25, Section 3.)

Marx saw clearly that accumulation and deepening of capital require continuous and elastic availability of labor, at a reasonable cost. The institution of the reserve army serves this purpose, and underemployment is seen as functional to capitalism. The implication is that this classical economy is capital-constrained in Leontief's sense, but labor-constrained in the sense that the growth rate of output converges to (or fluctuates around) the growth rate of the effective labor force, where (at least) $n$ is considered exogenous and constant. ${ }^{6}$

\footnotetext{
${ }^{5}$ Evaluated at the steady state, the trace of the Jacobian matrix vanishes. Hence, the eigenvalues are purely imaginary, and the trajectories of the system present a center, or a closed orbit, or a conservative oscillation, the location and shape of which depends on parameter values and initial conditions. See Lorenz (1993, p.61-67) for a discussion of stability. Further, while the state variables never reach their respective steady states, (ii) and (iv) apply on average.

${ }^{6}$ Harrod (1939, p. 30) writes that "[the natural rate of growth] is the maximum rate of growth allowed by the increase in population, accumulation of capital, technological improvement and the work/leisure preference schedule, supposing that there is always full employment in some sense." The latter qualification - "in some sense"-is critical in the current context: the Goodwin model
} 
The reserve army mechanism is crucial here: labor is elastically supplied at the prevailing real wage at a point in time, but a diminishing pool of surplus labor leads to real wage increases. Initially, the reserve army's ranks were filled by freed serfs, today, they are replenished through spurts in technological advancement and recurrent crises. While Marx connects the resulting "periodicity" (ibid.) to a Malthusian population mechanism, this does not play a central role in Goodwin's growth cycle. Instead, high real wage growth (relative to labor productivity growth) manifests with the threat of reserve army depletion, and directly reduces profitability and in consequence accumulation and employment. The collapse of employment restores the reserve army, weakens real wage growth, and thus buttresses profitability. Round and round it goes.

This narrative has been refined and reshaped in various ways. Key issues concern whether aggregate demand plays a role, whether the natural rate of growth is considered as endogenous, whether monetary factors are included, and whether specific formalizations lead to endogenous cycles or not, and build on microeconomic optimization or not.

To begin, consider the natural rate of growth. If its components are exogenous, the long run growth performance of the economy depends on "manna from heaven," just as in the neoclassical textbook model. However, the growth rate of labor productivity can be modeled as endogenous to the labor share. Several papers have extended Goodwin's original to include this theory of induced innovation, while maintaining the classical assumption of Say's Law. Shah and Desai (1981) and van der Ploeg (1987) were early contributions; more recently, Foley (2003); Julius (2005); Tavani (2012) and Zamparelli (2015), among others, have pursued this line of research. Important conclusions are that (i) the conservative oscillation, extended and altered in this fashion, collapses to a (slowly) convergent cycle that nevertheless retains its counter-clockwise orientation in $e, \psi$ plane; and that (ii) the long run growth rates of output and capital now increase in the labor share. This is a critical issue: there is a negative association between labor share and accumulation in the short run and over the course of the cycle, but, with technical change induced by a higher labor share, the key variables can be linked positively at the steady state and in the long run. (We will pick this issue up in detail in Section 5.2.)

Further, Tavani (2012) presents a model that generates out-of-steady-state dynamics with Goodwinian characteristics while being micro-founded. Capitalists smooth consumption via intertemporal optimization, and, in consequence and as in Foley and Michl (1999), consume a constant portion of their wealth. Real wages, in turn,

features a constant employment rate in steady state, but the cyclical variations around that rate maintain a sufficiently large reserve army to protect profitability, generate sufficiently strong real wage growth to produce the profit squeeze, and maintain a stable labor share in the long run. Nevertheless, and as Solow (1990, p. 37) summarizes, while profit rate and capital productivity remain constant, "it is not so bad being a capitalist" in a Goodwinian world. 
are determined by Nash bargaining, and the representative firm's choice over the direction (but not the intensity) of technical change optimizes the rate of unit cost reduction. The resulting steady state features a balanced growth path, and satisfies the Kaldor facts - and, qualitatively, produces the counter-clockwise cycle in $e, \psi$.

In this literature, the model has no independent investment function, and aggregate demand does not matter. However, Goodwin (1951) himself clearly recognized that it does. Later, Goodwin (1989) sketched a possible synthesis of the classical growth cycle and Keynesian aggregate demand. Skott (1989) presents an important advance along these lines. The profit share is seen as adjusting instantaneously to goods market disequilibrium. A rise in the profit share triggers output growth (investment as expenditure), which then feeds into the capital stock (investment as capacity). The income-capital ratio and the employment rate form the dynamical system, the solution of which implies a limit cycle. Since the functional distribution of income responds instantaneously to the income-capital ratio, it also implies the Goodwin pattern in employment rate and labor share, albeit here without a profit squeeze through real wage bargaining.

In a similar modeling framework, but with a clear emphasis on the profit squeeze mechanism, von Arnim and Barrales (2015) provide critical discussion. These authors draw heavily on Barbosa and Taylor (2006), who juxtapose the dynamics of the labor share with a macroeconomic rate of capacity utilization (instead of the employment rate), proxied by a measure of the output gap. ${ }^{7}$ Barbosa and Taylor (2006), building on earlier stagnationist literature, hypothesized a more flexible model structure, according to which output growth might be "wage-led," and the cyclical movement between activity variable and labor share reversed. However, and as subsequent discussion demonstrates, the empirically relevant case is the distributive cycle. ${ }^{8}$

Peter Flaschel and collaborators have sought to directly build on Goodwin (1989). Detailed expositions of a marriage of the classical growth cycle and Keynesian business cycle dynamics are presented in Flaschel $(1993,2009,2015)$ and Chiarella and Flaschel (2000). In particular, Flaschel (2009, chap.4) provides a comprehensive overview of the reserve army mechanism and the resulting distributive cycle - from Marx's theory of cyclical accumulation to the inclusion of Harrodian multiplier-

\footnotetext{
${ }^{7}$ If $\sigma \equiv Y^{*} / K$ as defined above is constant, and $U \equiv Y / Y^{*}$ is the rate of capacity utilization, $u \equiv \sigma U=Y / K$ features the same dynamics as the (unobservable) rate of utilization. Many empirical applications primarily concerned with business cycles simply utilize a detrended measure of $Y$.

${ }^{8}$ The stagnationist (or neo-Kaleckian) literature is extensive; see Taylor (2004) and Blecker and Setterfield (2019) for book-length treatments. The latter authors label Barbosa and Taylor (2006) and subsequent literature as neo-Goodwinian, and contrast it in this manner from the stagnationist strain. It should be emphasized that the direction of the cycle is a theoretically and empirically distinct issue from potential long run causal links between the functional distribution and macroeconomic perfomance; see discussion further below.
} 
accelerator dynamics.

Further, these authors extend such Keynesian distributive cycles to encompass monetary factors. Crucially, neither in theoretical nor in empirical approaches does the inclusion of, for example, a monetary policy rule alter the nature or direction of the distributive cycle (for examples, see Franke and Asada, 1994; Proaño et al., 2006, and the books just cited). Indeed, the two indispensable features of the distributive cycle - profit-driven accumulation and the reserve army mechanism - can be viewed as compatible with elements of the neoclassical synthesis, as represented by an interest-sensitive investment function and separate wage and price Phillips curves. The resulting real wage growth late in the cycle then needs to be sufficiently strong to provide the profit-squeeze turning point (see Flaschel and Krolzig, 2006; Tavani et al., 2011, and further discussion below).

In summary, theoretical motivations for a distributive cycle can be found across different literatures: classical, post-Keynesian and old-Keynesian theories contain ideas, utilize methods, and build on propagation mechanisms that make a distributive cycle possible. ${ }^{9}$ It is then secondary (for our purposes) whether such a distributive cycle features a closed orbit, a limit cycle, or convergent dynamics - as long as they qualitatively conform to what we might call the Goodwin pattern (see Flaschel, 2009, p. 3); moreover, it is secondary (for our purposes) which of these specific data-generating mechanisms is most relevant - as long as the distributive cycle is detected in the data. The next two sections are concerned with that, and Section 5 outlines a current research agenda.

\section{Data}

This section presents data on economic activity and functional distribution of income for the post-war US macroeconomy. We employ continuous wavelet transform (CWT) and Fourier transform. Figures below report power spectra based on both. These demonstrate a frequency peak around ten years for all series, and thus motivate our subsequent focus on filtering that appropriately captures it. The common ten year frequency peak for activity and labor share measures also justifies the variables' relation, and, as will be seen in Section 4, the Goodwin pattern clearly manifests at frequencies from 4-16 years.

We utilize standard measures of employment rate and output gap to describe economic activity, discussed in detail in Section 3.1. Further, we propose six different

\footnotetext{
${ }^{9}$ New-Keynesian theory builds on an RBC baseline, which does not have strong propagation mechanisms. Nevertheless, the recent literature has sought to model fluctuations in income shares, which here correspond to a time-varying elasticity of substitution in CES-technology. We will not discuss this literature in detail, but refer to key empirical findings therein in Section 4 . For prominent examples of this line of work, see Young (2004); McAdam and Willman (2013); Growiec et al. (2018); León-Ledesma and Satchi (2019).
} 
measures of the labor share. These illustrate key differences and similarities: all labor share series show the ten year frequency peak. In consequence, the Goodwin pattern at this frequency is robust to differing approaches on measuring the labor share. However, their trends differ significantly, so that a discussion of longer run developments crucially depends on how the labor share is measured.

\subsection{Economic activity}

In line with theoretical motivations above, we put forth two different measures of macroeconomic activity: employment rate and output gap. We discuss both in turn: ${ }^{10}$

- Employment rate, labeled $e$ : The employment rate utilized here is the remainder to one of the civilian unemployment rate. The series "UNRATE" was obtained from the Federal Reserve Economic Database (FRED), for the sample period 1949:Q1-2020:Q1. The employment rate measured in this manner abstracts from trend changes that are evident even in the prime-age employment-to-population ratio due to the entry of women into the labor force.

- Output gap, labeled $u$ : The output gap utilized here is the log ratio of real GDP to the CBO's measure of real potential GDP. The series were obtained from FRED as "GDPC1" and "GDPPOT," respectively, for the sample period 1949:Q1-2020:Q1. Real potential GDP is constructed based on the assumption that both capital and labor are fully employed. In this sense, the series is not a measure of the rate of capacity utilization. The latter is the ratio of actual to full-capacity output - and thus dependent on full utilization of capital, but independent of full employment of labor. An alternative measure, more closely aligned with theory, would be the income-capital ratio. However, capital stock data is available only on an annual basis, and we therefore proceed with this standard proxy for macroeconomic activity.

The bottom two rows of Figure 1 show these activity series. The left panel reports the standardized time series, the middle panel its CWT power spectrum, and the right panel its Fourier power spectrum. Both methods provide - in short-variance decompositions in the frequency domain. (See Appendix A for details.) The Fourier power spectrum lists the period on the vertical axis. The wavelet power spectrum further decomposes the series across time, and hence shows years on the horizontal axis, and period on the vertical axis, while a higher "power" is signified by warmer colors. ${ }^{11}$

\footnotetext{
${ }^{10}$ Note that neither of these variables are perfect proxies of the utilization rate, which is in many theoretical approaches the key variable. See Nikiforos (2020) for a discussion and further references on the difficulties of measuring utilization, and potential alternatives.

11 "Period" is the time (years) it takes to complete a cycle, and "frequency" is its inverse: cycles per unit of time; i.e. longer (shorter) periods correspond to lower (higher) frequencies.
} 

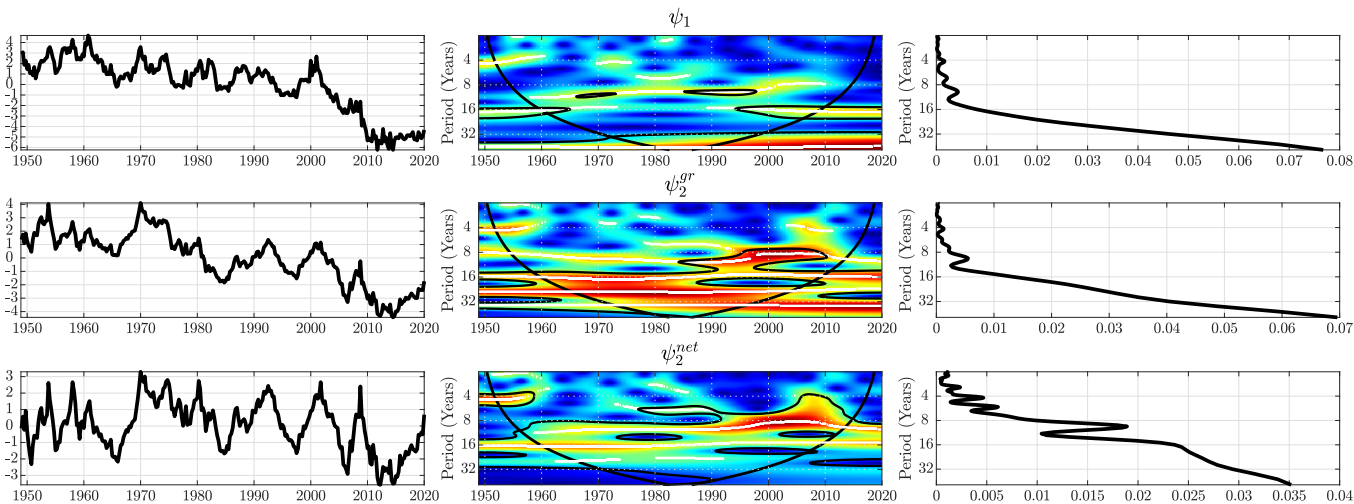

$\psi_{3}^{g r}$
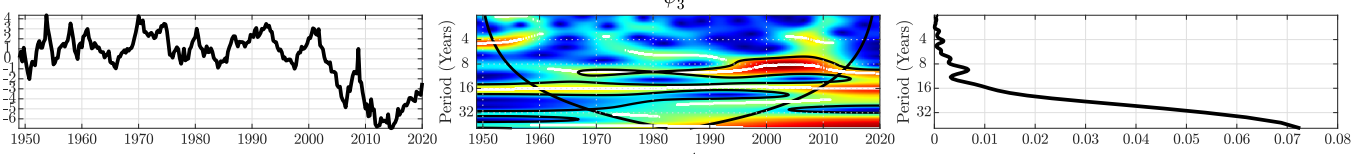

$\psi_{3}^{\text {net }}$
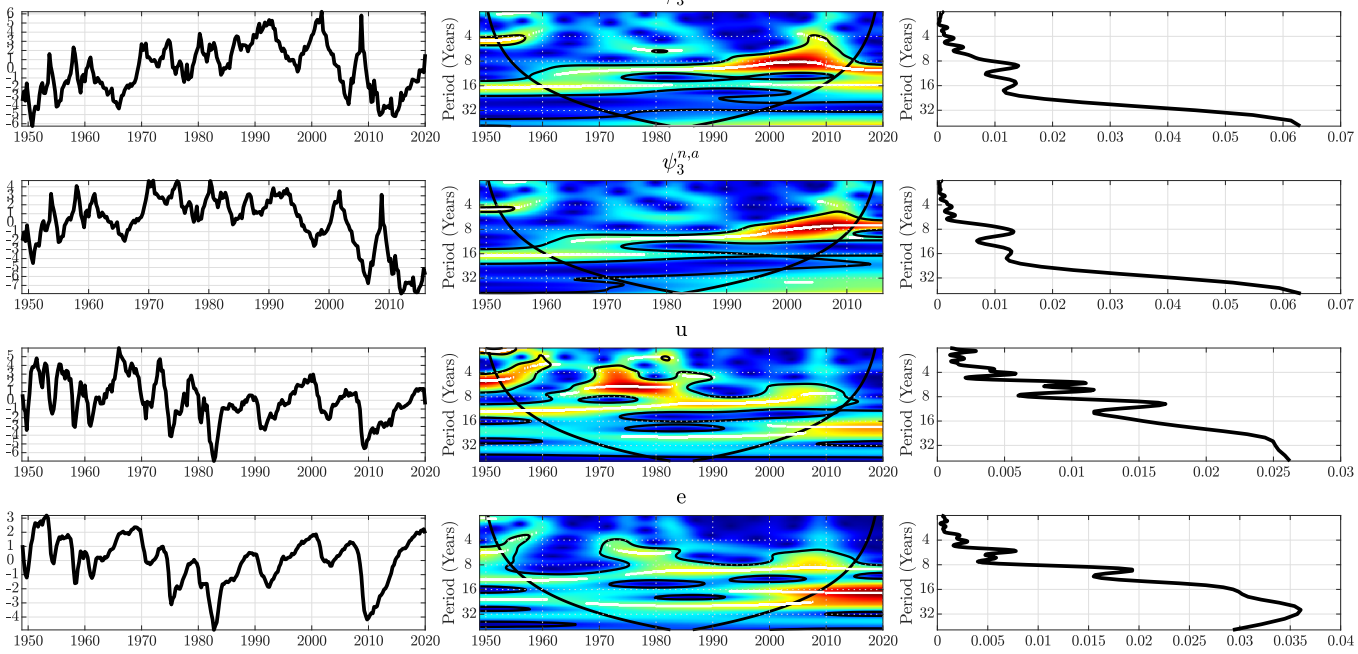

Figure 1: Output gap, employment rate and six labor shares: Top six rows are labor shares as in Section 3.2; bottom two rows are output gap $(u)$ and employment rate. The left panels shows the raw (standardized) time series. The middle panel shows the continuous wavelet power spectrum, where warmer colors signify higher power. Contours in black solid lines show where the power is larger than a $\operatorname{AR}(0)$ using the surrogate technique; white lines illustrate "ridges," i.e. the locally highest power across periods. The right panel reports the Fourier power spectrum. See Sections 3 for data sources and discussion, and Appendix A for details on wavelet methods.

As is evident in the rightmost panels, neither of these standard activity measures display significant variance at high frequencies, i.e., below three years. In contrast, both show an important frequency peak at about ten years, and - roughly - five year windows around that. The wavelet power spectrum also emphasizes the ten-year 
frequency, clearly visible in yellow for both series. ${ }^{12}$ The stagflationary episode in the 1970ies and the 2000s appear to highlight higher frequencies of about five years. These episodes are particularly pronounced for the output gap. Since roughly 2000, lower frequencies of about twenty years seem to have mattered more than earlier. However, given the lack of data towards the end of the sample one should probably not read too much into this (yet).

Crucially, these series are ratios. In both, the denominator absorbs important macroeconomic changes: labor force participation can vary significantly, and the repeated revisions to estimates of potential output in the wake of the Great Recession have invited criticism. However, our primary focus here is on the distributive cycle. For that purpose, these standard measures work, and, in summary, display frequency peaks at about ten years.

\subsection{The labor share of income}

The measurement of the labor share of income is a vexed question. In principle, it should simply report all income that is based on (paid) work, as a share of the appropriate aggregate. It is, however, not even conceptually clear what this means. For instance, considerable effort in the literature is spent on allotting a portion of income from "self-employment" to the labor share. From the perspective of classical political economy, this is questionable. The very definition of "labor" is that it can't but sell itself. Clearly, neither a store owner who also runs the register, nor the individually practicing lawyer or doctor do that. This petite bourgeoisie or, in some parts, professional class, is something else. To instead focus on the capital-labor employment relationship, one might want to stick to the corporate sector.

Further, some approaches include or exclude public employees, others import and production taxes, or depreciation, or certain activities (i.e., real estate: see Rognlie, 2015). Research in the classical political economy tradition might want to emphasize productive (as opposed to unproductive) activities, and hence exclude finance as merely redistributive (for an example, although not on the labor share per se, see Basu and Foley, 2013). Additionally, the dramatic increase in wage inequality raises the question whether a top sliver of salaries might not be better categorized as (distributed) profits, or, alternatively, rents. ${ }^{13}$ Barkai (2020, p.1), who argues "that

\footnotetext{
${ }^{12}$ The length of NBER reference cycles (trough-to-trough) for the entire post-war period amounts to about six years, whereas post-1982, cycles average almost nine years, confirming the lengthening of the cycle with much slower recoveries in the neoliberal era. However, the periodograms here strongly indicate a ten year frequency peak, not only for activity measures, but - see discussion in the following subsection-also very clearly for all labor share measures. We thank a referee to point out this discrepancy, but for our applications below follow the data rather than the NBER. It should also be noted that VAR models in Section 4.3 apply raw data.

${ }^{13}$ For data on wage inequality, see the extensive work following Piketty and Saez (2003), including Alvaredo et al. (2018). For our purposes, Table IV of Piketty and Saez (2003, p.26) is particularly relevant. An update of this table is available on Emmanuel Saez's website (see
} 
the shares of both labor and capital are declining and are jointly offset by a large increase in the share of pure profits," can be interpreted along these lines. ${ }^{14}$ Duménil and Lévy (2015) describe similar data trends on the basis of a tripartite class analysis, extending the capital-labor conflict to include a managerial class - which has successfully and significantly increased its income share in recent decades.

For more extensive discussions of these issues, see Gollin (2002); Gomme and Rupert (2004, 2007); Elsby et al. (2013); Mendieta-Muñoz et al. (2020, Section 2) and especially Mućk et al. (2018) in this journal. We largely follow the approach outlined in Gomme and Rupert (2004, p. 8), Gomme and Rupert (2007, p. 471, eq. 34) and Mućk et al. (2018, p. 964, eq. 4): income flows in gross value added are separated into unambiguous labor and unambiguous capital income, and ambigious income flows - proprietor's income, business current transfers, and production taxes - are assumed to be subject to the same distribution as the unambigious flows. These authors, however, prefer to focus on private employment and gross measures; for the sake of comparison, we also report measures that include public employment or exclude capital consumption. The latter is particularly important in light of shortening lifespans of IT capital, and the resulting increase in depreciation flows (Koh et al., 2020). Regarding the latter, Bridgman (2018, p. 2071) argues that net shares are appropriate, since "[u]sing net production only includes output which can be used for current consumption or expanding future production." In contrast, Mendieta-Muñoz et al. (2020) argue that depreciation presents an income flow at a point in time and hence should be included.

The following list provides details on the six estimates of the labor share proposed here:

- BLS headline measure: (1) $\psi_{1}$ is the Bureau of Labor Statistics' (BLS) so-called "headline measure" for the labor share in the non-farm business sector. It can be accessed as an index at FRED and directly from the BLS as a percentage. ${ }^{15}$ The headline measure includes only private activity, excludes agricultural activity, is gross, and assumes that hourly wages of the self-employed are the same as those in the corporate sector (Elsby et al., 2013, p. 9).

- Gross domestic income: (2) $\psi_{2}^{g r}$ is based on Table 1.10 of Bureau of Economic Analysis' (BEA) National Income and Product Accounts (NIPA), which reports gross domestic income by type of income. We follow the approach outlined above,

https://eml.berkeley.edu/〜saez/; accessed July 2020).

${ }^{14}$ Moreover, Barkai (2020) emphasizes that the commonly drawn on larger-than-unity elasticity of factor substitution would be consistent with labor and capital shares trading off against each other. His findings suggest that this is not the case. See also Raval (2017) and Chirinko and Mallick (2017) for evidence strongly in favor of an elasticity of substitution below unity and p. 32 below.

${ }^{15}$ The FRED series code is PRS85006173. See https://www.bls.gov/lpc/tables.htm, and the tab "NFBUS, All persons (level)" in the Excel file posted under "Labor productivity and cost measures" for the percentage share; accessed July 2020. 
and calculate total compensation (Line 2) as a share of the sum of compensation and unambigious capital income: net interest, rental income, corporate profits and capital consumption (Lines 11, 14, 15 and 21, respectively). Hence, $\psi_{2}^{g r}$ is gross, and apportions ambigious income as described above, but includes public employment. (3) $\psi_{2}^{\text {net }}$ is as $\psi_{2}^{g r}$, but further excludes depreciation.

- Corporate value added: (4) $\psi_{3}^{g r}$ is based on BEA-NIPA Table 1.14, which reports gross value added of domestic corporate business. We calculate this as the ratio of compensation (Line 4) to the sum of compensation and capital consumption, net interest and corporate profits (Lines 2, 4, 9 and 11). (5) $\psi_{3}^{\text {net }}$ is the net version of $\psi_{3}^{g r}$. (6) We further propose to adjust the labor share to exclude the top $1 \%$ of wage income (as in Barrales and von Arnim, 2017). We draw on updated Tables B.2 and B.5 of Piketty and Saez (2003) (see also footnote 13) to calculate the top 1\% share of wage income for the period 1949-2016, interpolate it to obtain a quarterly series, and calculate $\psi_{3}^{\text {net,adj }}$, the "bottom-99\%" version of $\psi_{2}^{\text {net }}$.

The top six rows of Figure 1 show these labor share series. The left panel reports standardized raw data, middle and right panel their CWT and Fourier power spectra, respectively.

A key observation is that every single one of these measures portrays significant cyclicality. Barrales and von Arnim (2017, Fig. 2, p. 201) shows similar labor share measures, with NBER reference cycles in gray, which further illustrate the relationship to the business cycle. Moreover, all measures show a pronounced frequency peak at about ten years; see the rightmost panels. The CWT power spectra in the middle panels confirms this stylized fact, but also emphasizes significant differences in the "power" at lower frequencies across the series. ${ }^{16}$ In a nutshell, these series have very similar cyclical properties, but show different medium and longer term trends. Results here thus confirm that "short-run properties of the labor shares are relatively consistent across the considered alternative definitions, [but] their [...] trends diverge substantially" (Mućk et al., 2018, p. 975). ${ }^{17}$ However, the pronounced fre-

\footnotetext{
${ }^{16}$ Analysis of the labor share in frequency domain has become more common. Gallegati et al. (2011) present an early - and relevant - application to the Phillips curve. Barrales and von Arnim (2017) were the first to apply discrete wavelet transforms and multi-resolution analysis to the functional distribution of income. Charpe et al. (2019) also present wavelet power spectra. Their longer sample period includes two world wars and hence highlights interwar macroeconomic gyrations. Despite this, the post-war period clearly features an important frequency band at about ten years, see Panel (a) of their Figure 1. Their labor share measure is based on Piketty-Zucman data, is net, and augments public and private compensation flows by the self-employment income ratio, as in Mendieta-Muñoz et al. (2020).

${ }^{17}$ Further, the preferred measure of the labor share displays a "hump-shaped pattern" (Mućk et al., 2018, p. 962). This is evident in our data most clearly for net "bottom-99\%" measure $\psi_{3}^{\text {net, adj }}$, and also in the aggregate labor share of private activity, excluding real estate, in Mendieta-Muñoz et al. (2020). This hump-shaped pattern is a critically important feature of relating the labor share to narratives about a post-war "golden age" of capitalism, and the subsequent neoliberal era. We agree with Mućk et al. (2018) in this regard; see also Kiefer et al. (2020) and Sections 4.2, specifically
} 
quency peak around ten years suggests that the classification of periodicities - with a "medium run" encompassing 8-50 years, Table 3, p. 974 - of said paper might not be ideal. Instead, we focus in the next section on a frequency band of 4-16 years, centered on the ten year peak.

\section{Evidence}

Here we summarize evidence for a distributive cycle. We provide selected empirical exercises. Our intent is to provide a clear and comprehensive frame of reference for discussion in the following Section 5. The key conclusion is that the distributive cycle is alive and well, despite the dramatic decline in the trend labor share, and despite a potential overall weakening of the reserve army mechanism.

We begin with a review of the most pertinent empirical results in Section 4.1. ${ }^{18}$ Second, two sub-sections update and restate the central results. In Section 4.2, we employ CWT methods to calculate the phase difference between activity and distribution. Results indicate a counter-clockwise cycle in activity-labor share plane for the 4-16 year frequency band, i.e.: the distributive cycle. In Section 4.3, two small-scale VARs for the US (1949:Q1-2020:QI) in $u, \psi$ and $e, \psi$ provide the standard impulse response function (IRF) results: (i) a shock to activity increases the labor share, and (ii) a shock to the labor share decreases macroeconomic activity, i.e.: the distributive cycle.

\subsection{Survey of the literature}

Before we delve into empirical results that directly build on Goodwinian theory, we briefly survey the broader literature. As noted (footnote 9), the DSGE literature connects the labor share to the elasticity of substitution of a CES production function, regarding both short and long run. Here, we focus entirely on papers speaking to short run fluctuations (rather than secular trends), and on the empirical results (rather than proposed theoretical mechanisms). That said, a consensus on these fluctuations appears to be emerging, and it broadly confirms that macroeconomic activity leads the labor share, i.e., the profit squeeze.

An important result is presented in Ríos-Rull and Santaeulàlia-Llopis (2010). The authors estimate a VAR, and specifically impose a bivariate shock to an otherwise standard RBC model. The IRFs in their Figure 1 (p. 934) show that the labor share responds negatively on impact to both a demand shock and a Solow residual shock, but then "overshoots its long-run average after five quarters, and it peaks

p. 21 , and 5.2 below.

${ }^{18}$ Such a review must be selective: the components of the labor share include nominal wages, the general price level and labor productivity, and as such ninety-nine percent of macro-papers could be relevant. Specifically, we will not include any detailed overview of the voluminous literature on Phillips curves, new-Keynesian or otherwise. 
at the fifth year [...], after which labor share slowly returns to its long-run average" (our emphasis, ibid.). The authors conclude that the labor share is quite volatile, is countercyclical, is highly persistent, and lags output. Colciago and Rossi (2015, Fig. 1, p. 1310) reproduce their result, and argue that real wages must respond slower, but ultimately stronger than average labor productivity to the upswing. León-Ledesma and Satchi (2019) also draw on this result, and replicate it in their estimation (and simulation) of a DSGE model with shocks to labor productivity and the relative price of capital. The "overshooting" of the labor share can be seen in their Figures 5 (p. 819) and 7 (p. 831).

For a similar result, see Shao and Silos (2014, Fig. 1, p. 779). Their lead-lag analysis of Hodrick-Prescott (HP) filtered series demonstrates that real GDP leads the labor share across a number of different measures of the labor share. Since the contemporaneous correlation is (weakly) negative, they conclude that the labor share is countercyclical. In contrast, the profit share is strongly procyclical. Mućk et al. (2018, p. 976 and Tables 5 \& 6) expand on these results, emphasizing that "the short-run labor share component is countercyclical, whereas the medium-run component is procyclical." ${ }^{\prime 19}$ Growiec et al. (2018, Table 1, p. 78) present the same result from a slightly different angle.

In summary, these different approaches all generate the same result. A business cycle upswing, proxied by a productivity or demand shock, or simply the growth rate of real GDP, decreases the labor share contemporaneously, but increases it with a lag. This is consistent with a key characteristic of the Goodwin pattern as discussed in Section 2: the activity variable leads the labor share to produce the profit squeeze.

In the literature on the distributive cycle, the issue is often approached via empirical phase trajectories. Theory predicts a counter-clockwise cycle in $e, \psi$-space and $u, \psi$ space. Appropriately filtered time series, plotted in the plane, conform to this cyclical stylized fact. Early examples include Mohun and Veneziani (2006, Fig. 3, p. 15) and Barbosa and Taylor (2006, Fig. 1, p. 390). Both draw on HP-filtered series; the former in $e, \pi$, the latter in $u, \psi$. Zipperer and Skott (2011) provide a comprehensive overview of HP-filtered series, including the Goodwin pattern in $e, \pi$ and $u, \pi$ but also in $e, u .^{20}$ Tavani and Zamparelli (2015, Fig. 1, p. 208) show

\footnotetext{
${ }^{19}$ Note that terminology across these papers varies. As mentioned before, Mućk et al. (2018), following Comin and Gertler (2006), define the medium run to entail periodicities from 8-50 years. This lobs off the important ten year frequency peak from what we call the short run. In other words, our view is that highest frequencies (below 3 or 4 years) matter little; the short run is composed of periodicities 4-16 years; and all lower frequencies make up the medium and long run. The results in Mućk et al. (2018) and Growiec et al. (2018) cited here report the share of total labor share variance attributable to their definition of short and medium run frequencies, and their correlation with real GDP.

${ }^{20}$ These three cycles (in the US) all portray a clockwise pattern; see also Skott (1989), Tavani (2012), and von Arnim and Barrales (2015) for theoretical models that generate a clockwise $e, u$ cycle.
} 
HP-filtered $e, \psi$ phase trajectories, based on the non-financial business sector labor share. Barrales and von Arnim (2017, Fig. 4, p. 208) report results based on discrete wavelet transforms: the $4-8$ year components display very clear Goodwin patterns. ${ }^{21}$

A common theme in these contributions is to recognize that the distributive cycle unfolds at business cycle frequencies, if these are not unduly restricted to the highest frequencies. Cycles are robust to different measurement and methodological approaches, whereas longer run trends can differ wildly (see for example Mohun and Veneziani, 2006, Section 6.4), an observation echoed in Section 3.2 above. Further, a common focus on cycles does clearly not preclude "shifts of the underlying equilibria" (Tavani and Zamparelli, 2015, p. 210). In summary, such empirical phase trajectories provide strong intuitive motivation, but - given the absence of statistical tests - do not offer clear evidence.

Estimation of econometric models does, and we will now selectively review key contributions. We will focus on research that directly builds on classical-Keynesian approaches, and among these not consider studies that assume the functional distribution of income to be exogenous. Given preceding discussion, this is wrong both in terms of theory and empirics. ${ }^{22}$

Emphasis is thus placed on VAR methods. In this context, (ordering) restrictions and the corresponding theoretical priors are critical. To preface conclusions, all studies with orderings in line with preceding discussion confirm the Goodwin pattern. The critical insight here is that correct orderings always emphasize contemporaneous effects from the labor share on activity, but not vice versa. It is based on the assumption that the labor share converges more slowly than the activity variable to the respective steady state: even if labor productivity varies rapidly and procyclically, real wages catch up to an upswing only with a significant lag. This is implicit in theory and empirics across a wide number of approaches. We will thus refer to this as the standard ordering.

Further, when the two-dimensional interaction between activity and labor share is

\footnotetext{
${ }^{21}$ An update to include the most recent decade reveals no change: the counter-clockwise cycle persists throughout both expansions in the 2000s for $e, \psi$ and $u, \psi$ at 4-8 year frequencies-though the most recent increase in the labor share in the wake of the Great Recession appears particularly weak. Details are available upon request.

${ }^{22}$ Some Kaleckian and all supermultiplier approaches see $\psi$ as exogenous; see the aforementioned Blecker (2016), Blecker and Setterfield (2019), and Freitas and Serrano (2015). Granger causality tests reported in Barrales and von Arnim (2017, Table 1) indicate that bidirectional causality between activity and labor share exists at almost any frequency. Further, if the labor share is assumed to be exogenous, the lead-lag relationship between the key variables could imply measurement of the profit squeeze when the investigator is targeting the growth regime; see also subsequent paragraphs. For a Kaleckian approach that considers the distribution of income as endogenous, see Nikiforos and Foley (2012). Their results find important nonlinearities, but can also be seen as broadly consistent with neo-Goodwinian results. Indeed, many authors would argue that neo-Goodwinian theory is compatible with Kaleckian ideas (Barbosa and Taylor, 2006; von Arnim and Barrales, 2015).
} 
considered, two off-diagonal signs are relevant. To use terms commonly applied in the literature, a negative effect from the labor share on activity is labeled "profit led" (PL henceforth), and a positive effect from activity on the labor share "profit squeeze" (PS). These are shorthand signifiers for the key mechanism underlying the distributive cycle, see p. 5 in Section 2 above, and we will utilize them in subsequent paragraphs.

Barbosa and Taylor (2006) presents an early and influential paper, laying out relevant neo-Goodwinian theory and empirics. The authors employ a two-dimensional VAR, and find support for a PL/PS regime for most of the post-war US period. However, their estimation strategy does not include contemporaneous interactions, and is thus not suitable for causal interpretations (see also Basu and Gautham, 2019, p. 9). Proaño et al. (2006) use GMM to estimate a "semi-structural baseline model," and report parameter estimates for the US (1960-2004) consistent with a PL/PS regime (see Table 5, p. 21). Kiefer and Rada (2015) estimate a panel VAR on thirteen OECD countries for the period 1976-2012; their results clearly indicate a PL/PS regime (see Table 1, p. 1341). In the same theoretical context, Carvalho and Rezai (2016) investigate the role of a changing size distribution of income. The authors employ a threshold VAR for a utilization proxy and the labor share in the US (1967-2010), where the threshold variable is the Gini coefficient, and the standard ordering is applied. Findings indicate that the US features a PL/PS regime, see Figures 5 and A1 (p. 500 and 504, respectively), and moreover that a higher Gini coefficient strengthens both effects. Utilizing machine learning methods, Barrales and von Arnim (2020) investigate whether US post-war data support the existence of an endogenous distributive cycle in activity and labor share, and conclude with a qualified yes.

In a recent and carefully executed paper, Basu and Gautham (2019) focus on the effect of a shock to the labor share on activity variables in the US macroeconomy, 1973-2018. Across several models and methods, results unequivocally confirm a $\mathrm{PL} / \mathrm{PS}$ regime. The first model is a three variable recursive VAR in labor share (as our $\psi_{3}^{\text {net }}$ ), utilization (as our $u$, though not logged), and the real exchange rate. Two orderings are applied, and both see the utilization rate impacted contemporaneously by both other variables. Figures 2 and 3 (p. $21 \& 22$ ) show results, and both indicate PL/PS. An augmented six variable VAR with a modified identification strategy based on Christiano et al. (1999) focuses entirely on the effects of a distributive shock. The authors report that utilization, employment and accumulation respond negatively to a labor share shock, i.e. a PL regime.

Other recent research has sought to decompose the labor share in order to disentangle separate real wage and productivity effects. The focus of Mendieta-Muñoz et al. (2020) is to identify structural innovations in a four variable structural VAR (SVAR), and subsequently assess the impact of these exogenous variations on the labor share itself, and specifically across two different periods (1948-1985, and on to 2018). 
However, the four variable SVAR speaks directly to this literature; restrictions are motivated on the basis of neo-Goodwinian theory, and include a contemporaneous effect of output on labor productivity (see next paragraph). Figure 1 (p. 23) shows IRFs. For the period 1948-1985, results indicate a negative (positive) effect of a real wage (labor productivity) shock on output, and a positive effect of output on real wages; i.e. PL/PS. In the more recent decades since 1985, the effects of real wages on output and vice versa are not significant, but labor productivity maintains its strong and positive effect on output. In summary, these results suggest a distributive cycle, but with profit squeeze distribution and profit led activity weakened throughout the neoliberal era.

Cauvel (2020) finds a PL/PS regime for the US (1947-2016) with the standard ordering in a two variable VAR (see Figure 4, p. 26), and finds a PL/PS regime also in a three variable VAR that retains the baseline assumption of the activity variable being causally posterior to real wage and labor productivity (Fig. 5, p. 31). The author then motivates a reversal of ordering between activity and labor productivity, on the grounds that real wages indeed adjust more slowly, but demand should affect labor productivity contemporaneously. Results based on this ordering do not any longer support a distributive cycle - but both three variable models feature labor productivity effects that are difficult to reconcile with theory, and do not pass standard specification tests (Fig. 6, p. 33). ${ }^{23}$

Blecker et al. (2020) also decompose the labor share, in their application into firm's target mark-up and unit labor costs. The authors provide GMM estimation results that dispute the distributive cycle: an exogenous decrease in monopoly power and an exogenous increase in unit labor costs positively affect private aggregate demand. Their results are an outlier, and based on a model with a variety of features and extensions that make it difficult to compare. ${ }^{24}$

In summary, and as argued at the outset, ordering is critical. The standard ordering is well-grounded in theory, and estimations based on it generally fit the data well. This is not surprising, given the extensive evidence that activity leads the labor share at business cycle frequencies. Further work in this vein could seek to clarify the role of extended or decomposed models. It could be useful to deepen our understanding across different periods and countries. ${ }^{25}$ But there is little doubt that the distributive

\footnotetext{
${ }^{23}$ Similarly, Stockhammer and Onaran (2004) utilize an ordering that sees activity as causally prior to distribution, and find no significant effects between distribution and demand.

${ }^{24}$ Cauvel (2020) and Blecker et al. (2020) draw on Lavoie (2017), who provides an insightful review of these debates from a Kaleckian perspective, and is cited in these papers to say that literature on the distributive cycle has paid insufficient attention to procyclical labor productivity. We disagree: the labor share falls throughout the trough, and provides the lower turning pointwhether this arises from lower wages (as in the baseline model), or a procyclical labor productivity effect, is secondary. See Barbosa and Taylor (2006) and Flaschel (2009, Chapter 9) for models with procyclical labor productivity, possibly implicit in Okun's Law.

${ }^{25}$ All of the empirical work presented in this paper and specifically this section focuses on the
} 
cycle persists throughout the post-war US.

\subsection{Wavelet coherence}

In this section, we provide new evidence on the distributive cycle: based on the continuous wavelet transform (CWT), we calculate the phase difference between activity variable and labor share measures. Results clearly indicate the counterclockwise cycle in activity-labor share plane in the 4-16 year frequency band, i.e. the distributive cycle.

In brief, CWT is a transform that maps a time series from the time domain into the time-frequency domain. Wavelet methods perform a spectral estimation that is time dependent, revealing how different periodic components change over time (AguiarConraria and Soares , 2014). Two important time-frequency tools for bivariate time series are the wavelet coherence and the phase difference, which have their counterpart in the time domain as correlation and lead-lag analysis, respectively. Wavelet coherence emphasizes time-frequency regions at which a pair of time series have stronger correlation, and the phase difference provides information about delays of the oscillations of the two series, and, as we will see, the direction of the cycle.

Figure 2 shows the wavelet coherence (first column) and the (average) phase difference for the period from 4 to 16 years (middle column) and from 16 to 32 years (third column). The four labor share measures employed here include three gross measures: the headline measure $\psi_{1}$, the share based on gross domestic income $\psi_{2}^{g r}$ and the share based on corporate gross value added $\psi_{3}^{g r}$. While there are good arguments to use net labor share measures, we focus here on gross measures because the output gap is also based on real gross product. We provide one net measure for the sake of comparison. The top four rows show results vis-à-vis the output gap $(u)$, and the bottom four vis-à-vis the employment rate $(e)$.

The wavelet coherence in the left panels shows strong "correlations" at business cycle frequencies. The association is very similar for output gap and employment rate, and weakest (i.e., mostly blue across frequencies) in the late 1980ies and into the 1990ies. Further, the coherences appear to be more pronounced around an eight year period than for the univariate wavelet power spectra, where the ten year period was most prominent. Still, several measures show intermediate (i.e., yellow) coherence at that frequency. The $u, \psi_{3}^{\text {net,adj }}$ association is an exception, with a strong red band of coherence right around the ten year frequency.

post-war US macroeconomy. Other advanced countries have been investigated, with mixed results. For example, one might expect European countries with larger government and trade shares in GDP to feature less pronounced cyclicality of this type. In contrast to this, Rada and Kiefer (2016, Table A.3, p. 1349) report results for an OECD panel that indicate profit led activity for all countries. However, we do agree with the referee who suggested to consider this issue that the US is the relevant "capitalist test case." 

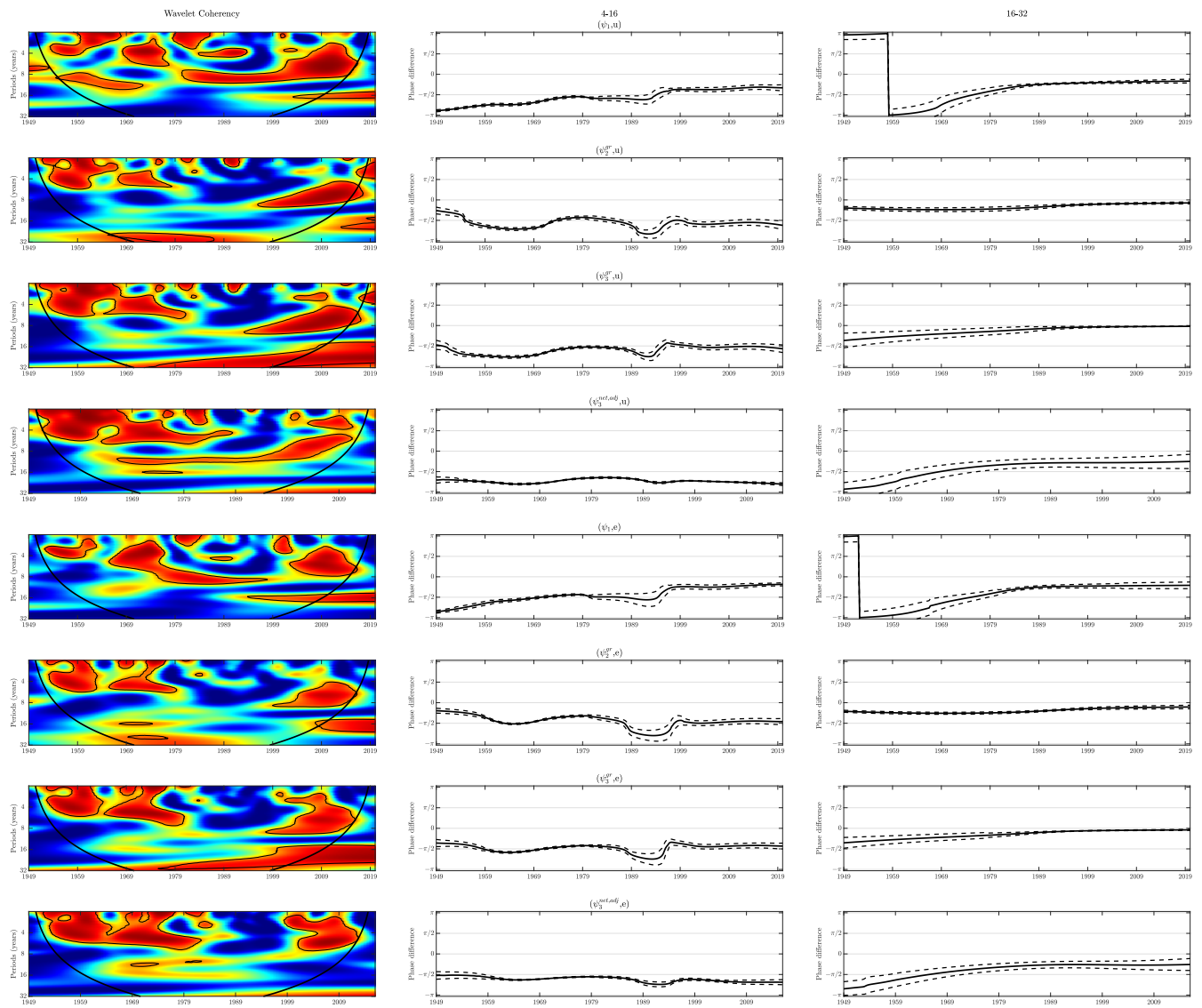

Figure 2: Wavelet coherence \& phase difference: Left panels show wavelet coherence between an activity measure and a labor share, where warmer colors represent stronger coherence. Middle and right panel report phase difference between the same measure at 4-16 and 16-32 year frequency bands, respectively; dashed lines indicate $5 \%$ confidence intervals. Top (bottom) four rows are output gap $u$ (employment rate $e$ ) vis-à-vis four labor shares. A phase difference at or near $-\pi / 2$ implies the Goodwin pattern: a counterclockwise cycle in activity-labor share space. See Sections 3 for data sources and Section 4.2 for discussion; Appendix A provides formal details. 
Importantly, the middle column of panels indicates an average phase difference for the period $4-16$ years between $(0,-\pi)$ for all variable pairs. For most variable pairs, the average holds steady at about $-\pi / 2$. The phase difference between $u$ and $e$ and the BLS headline measure (row 1 and 5) rises steadily from just above $-\pi$ to just above $-\pi / 2$ across the post-war period. The phase difference between the two activity measures and the net labor share $\psi_{3}^{\text {net,adj }}$ falls more consistently between $(-\pi / 2, \pi)$.

Aguiar-Conraria and Soares (2014, Fig. 3, p. 356) explain the relationship between the phase difference (in the considered frequency band) and the angle (i.e., the vertical axis of middle and right column of panels in our Fig. 2). In our variable dimensions, this implies that activity leads the labor share when the phase difference falls between $(-\pi / 2,0)$, or between $(\pi / 2, \pi)$, whereas the labor share is leading elsewhere. Further, for a phase difference between $(-\pi / 2, \pi / 2)$ the series are "in phase," i.e. are on average increasing or decreasing together. Elsewhere, they are "out of phase," and hence are on average moving in opposite directions. (Further details and references are supplied in Appendix A.)

As is apparent from the panels in the middle colum, the phase difference is at or near $-\pi / 2$. Importantly, even a phase difference below the threshold of $-\pi / 2$ implies the counter-clockwise Goodwin pattern: the two-dimensional model takes account of the profit squeeze distribution and profit led activity. To illustrate this, Appendix B provides phase differences of data generated by several theoretical models. Including white noise allows us to report probability distributions of the phase difference. Models with profit squeeze distribution and profit led activity (which display a counter-clockwise cycle in activity-labor share plane) feature a distribution of phase differences that peaks at or near $-\pi / 2$. This stands in stark contrast to a model with short run wage led activity, which features a phase difference distribution with single mode near $+\pi / 2$, and a model with short run wage led activity and a profit squeeze, which features a phase difference with a single mode at zero. ${ }^{26}$ In summary: despite the documented weakening of the PL/PS mechanisms during the neoliberal era, the distributive cycle is observed in this frequency band across all variable pairs and the entire post-war period.

Lastly, the right column of panels reports the phase difference in the 16-32 year frequency band. When paired with the headline measure $\left(\psi_{1}\right), u$ and $e$ show some sensitivity to the starting point of the sample. With those two (short) exceptions, the phase difference is consistently negative, and for several variable pairs increases from the range $(-\pi,-\pi / 2)$, where the labor share leads activity, to the range $(-\pi / 2,0)$,

\footnotetext{
${ }^{26}$ The latter model has two negative real roots, since the off-diagonal elements of the Jacobian have the same (positive) sign. See also discussion in Section 5.1. The first wage led model is paired with what is generally termed "forced saving," i.e. a nullcline for the labor share that is declining in activity. In other words, this model has complex roots.
} 
where activity leads the labor share. ${ }^{27}$

Charpe et al. (2019) also show wavelet coherencies. Their sample on the US covers the period 1898-2010. Figure 3a (p. 12) shows results, including arrows that indicate the phase difference. Arrow-tip down indicates that activity leads the labor share. Their activity variable, however, is real GDP growth, and that matters: the phase difference across periods and over time almost everywhere suggests that the labor share leads growth. In contrast, our analysis based on $u$ and $e$ indicates that activity leads the labor share for large portions of the post-war period. ${ }^{28}$

Similarly, Santos and Araujo (2020, Fig. 1, p. 277) report wavelet coherencies, although here again in a neo-Goodwinian context. Results suggest that coherence is strongest at high frequencies (i.e., shorter than 8 years), are overall relatively weak, but where significant, clearly indicate that the activity variable leads the labor share. However, all series enter as first differences (which could be seen as unnecessary especially for the Federal Reserve's measure of capacity utilization).

Both these studies conclude that the labor share has a positive effect on growth in the long run. Charpe et al. (2019) claim - on the basis that labor share leads growth at low frequencies - that the functional distribution is exogenous to growth, and can be used as explanatory variable in growth regressions. The authors thus demonstrate that high labor shares coincide with high periods of growth. Santos and Araujo (2020), on the other hand, base the conclusion on bivariate Granger tests on wavelet components, which Barrales and von Arnim (2017) also reported (without the associated claims).

Kiefer and Rada (2015) and Kiefer et al. (2020) investigate the question of the long run association between distribution and growth conditional on the short run Goodwin pattern. The former document the possibility that steady states of labor share and output gap declined together, while the distributive cycle unfolds around them (Fig. 6, p. 1343). The latter paper estimates the decline of a measure of potential output growth rate in recent decades within a model that conditions the long run on business cycle interaction, and thus connect the apparent long run positive correlation between activity and labor share to the distributive cycle.

\footnotetext{
${ }^{27}$ These results should be compared to the top left panels in Figures 6 and 7 of Barrales and von Arnim (2017, p. 209), which show a complete "Goodwin cycle" each between these same activity measures and the labor share in corporate net value added for the period 1948-1980; post-1980 no such cycle arises.

${ }^{28}$ Further, the level of real GDP also clearly leads the labor share. Details are available upon request. The growth rate of real GDP emphasizes high frequency components, and hence does not display the ten year frequency peak to the extent that output gap and employment rate and the labor share measures do. It is possible that the reversed relationship is resulting therefrom. On the other hand, Mendieta-Muñoz et al. (2020) use quarterly growth rates in their four variable SVAR, and nevertheless find evidence for the distributive cycle. Future research could seek to further elucidate the connections between these related but different applications.
} 
We do not believe that any of these methods provides conclusive evidence, but believe that the underlying hypothesis is correct: a positive link between the labor share and macroeconomic performance exists at the steady state. Our view is that the positive link arises out of the profit squeeze mechanism cum technical change over the distributive cycle. We return to this issue in Section 5.2.

\subsection{Vector autoregressions}

This section reproduces and updates standard results from vector autoregression (VAR) models. Our intent is to study the dynamic interactions between the labor share of income $\psi_{t}$, and macroeconomic activity, proxied by either the output gap $u_{t}$ or the employment rate $e_{t}$. We report results with one labor share measure, based on gross domestic income $\left(\psi_{2}^{g r}\right)$. Output gap is the log ratio of real GDP to CBO's estimate of real potential GDP, and employment the remainder to one of the civilian unemployment rate. (See Section 3 for further details on the data series.) The quarterly sample covers the period 1949Q1-2020Q1. All three series enter the estimations in levels.

The reduced-form VAR models can be depicted as follows:

$$
\mathbf{z}_{\mathbf{t}}=\gamma+\sum_{i=1}^{l} \mathbf{C}_{\mathbf{i}} \mathbf{z}_{\mathbf{t}-\mathbf{i}}+\mathbf{e}_{\mathbf{t}}
$$

where $\mathbf{z}_{\mathbf{t}}=\left(\psi, x_{t}\right)^{\prime}$ and $x_{t}$ corresponds to a variable that measures economic activity, that is, either $u_{t}$ or $e_{t} ; \gamma$ and all the $\mathbf{C}_{\mathbf{i}}$ are the reduced-form coefficients; and $\mathbf{e}_{\mathbf{t}}$ represents the vector of mutually correlated reduced-form residuals. ${ }^{29}$

We first considered Likelihood Ratio tests in order to determine the lag length for the VAR models that consist of $\left(\psi_{t}, u_{t}\right)^{\prime}$ and $\left(\psi_{t}, e_{t}\right)^{\prime}$, which indicated that the optimal lag lengths were three and two, respectively. However, both models presented serial correlation problems at the $5 \%$ according to serial correlation Lagrange Multipliertype tests. Hence, we considered instead VAR models with eleven lags for the output gap model and fifteen lags for the employment rate model. These did not present problems of autocorrelation. ${ }^{30}$

\footnotetext{
${ }^{29}$ The VARs presented in this and all subsequent sections were run with all variables in levels or ratios where applicable, i.e., without paying attention to the order of integration of the series. This approach is in line with current practices; for examples and further discussion, please see Sims et al. (1990) and summaries of this discussion presented in Enders (2015); Brooks (2019).

${ }^{30}$ Although relatively large lag lengths were needed to correct for serial correlation in the VAR models, fifteen and eleven lags with quarterly data mean that the dynamics of the estimated models incorporate approximately four and three years of data. This is appropriate for the study of business cycle fluctuations. Moreover, our sample size contains 285 observations, which implies that we can carry out statistical inference since the number of parameters estimated is always considerably smaller than the sample size.
} 


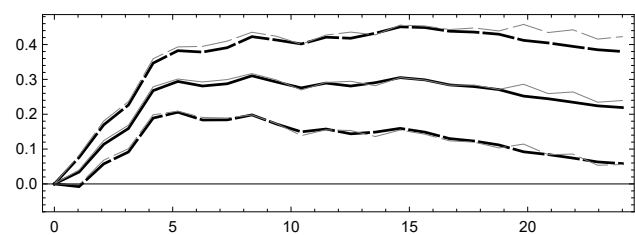

(a) Response of $\psi$ to $u$ shock

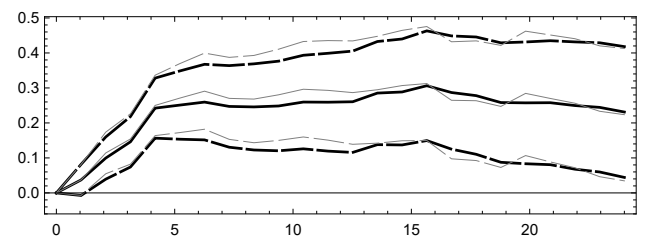

(c) Response of $\psi$ to $e$ shock

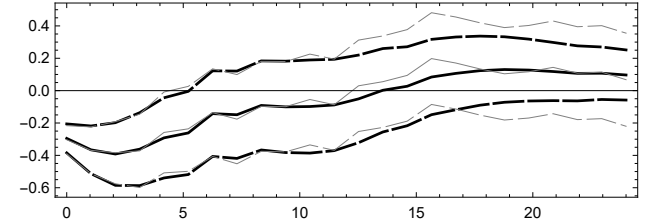

(b) Response of $u$ to $\psi$ shock

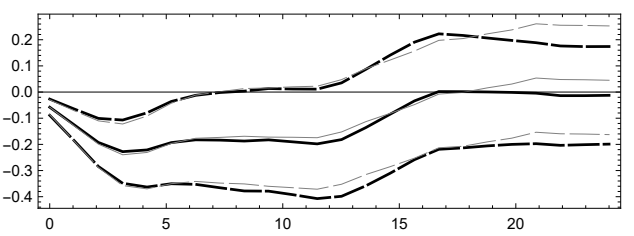

(d) Response of $e$ to $\psi$ shock

Figure 3: IRFs from VAR and LPs, standard ordering. Each panel shows IRFs from VAR (black) and LPs (gray). Variable order of the Cholesky decomposition is labor share $\longrightarrow$ activity. For VAR IRFs, dashed lines are 95\% confidence intervals, constructed via Monte Carlo simulations with 2000 replications; for LPs, these are marginal error bands. Horizontal axis shows quarters ahead in all figures. Top row is $u, \psi$-interaction, bottom $e, \psi$; we do not report the response of each variable to its own shock. See Section 4.3 for discussion.

We study the dynamic interactions between the variables of interest via IRFs derived from an orthogonalization of shocks that uses the Cholesky decomposition method of Sims (1980). We first apply the "standard ordering" of the variables in the VAR models (see p. 16 above): $\psi_{t} \rightarrow x_{t}$, which implies that the labor share (that is, the distributive variable in the system) can affect contemporaneously either the output gap or the employment rate (that is, the economic activity variable in the system), but not vice versa. (See also Section 4.1, especially p. 16ff above.)

We compute IRFs both via VAR and local projections (LPs), to report a robustness check. Since Jordà (2005), LPs have become a commonly used alternative to study the propagation of structural shocks. In brief, instead of using one set of VAR coefficients as in the IRF technique, LPs estimate a new set of estimates for each horizon, thus being more closely associated with multi-step forecasting. LPs collect new estimates for each forecast horizon by regressing the dependent variable (vector) at horizon $t+h$ on the information set at $t$; thus, the projections of forward values of the dependent variable (vector) on the information set are local to each horizon. Initially, it was argued that VARs and LPs are conceptually different, but the more recent literature demonstrates that the two methods in fact estimate the same population and sample IRFs (see also Mendieta-Muñoz et al., 2020, Section 5 ), and thus provide a suitable robustness check for VAR results. Figure 3 shows the key IRFs obtained from the models that considered $\left(\psi_{t}, u_{t}\right)^{\prime}$ in the top row and 


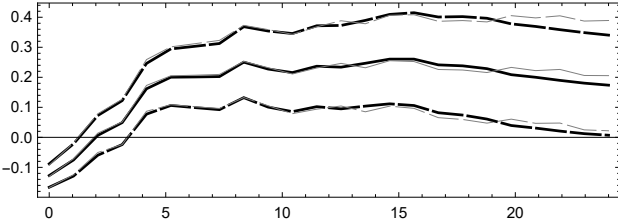

(a) Response of $\psi$ to $u$ shock

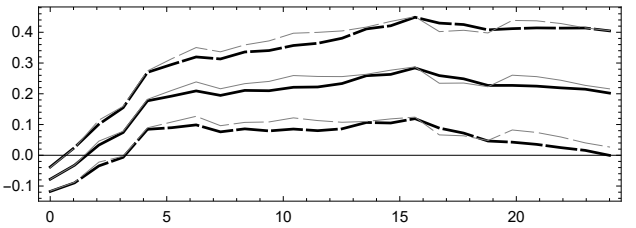

(c) Response of $\psi$ to $e$ shock

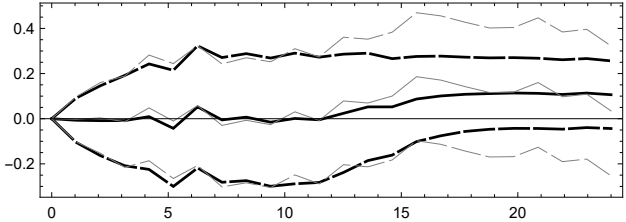

(b) Response of $u$ to $\psi$ shock

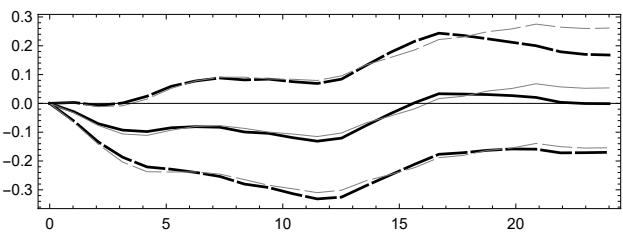

(d) Response of $e$ to $\psi$ shock

Figure 4: IRFs from VAR and LPs, reverse ordering. Each panel shows IRFs from VAR (black) and LPs (gray). Variable order of the Cholesky decomposition is activity $\longrightarrow$ labor share. For VAR IRFs, dashed lines are $95 \%$ confidence intervals, constructed via Monte Carlo simulations with 2000 replications; for LPs, these are marginal error bands. Horizontal axis shows quarters ahead in all figures. Top row is $u, \psi$-interaction, bottom $e, \psi$; we do not report the response of each variable to its own shock. See Section 4.3 for discussion.

$\left(\psi_{t}, e_{t}\right)^{\prime}$ in the bottom row, respectively.

These results indicate a distributive cycle. The left column of panels shows a strong and persistent profit squeeze effect, from an exogenous shock to either activity variable to the labor share. The labor share rises for four quarters, and remains significantly above its average for more than six years. This strongly suggests that the theoretical prior of a slowly adjusting labor share is correct. The right column of panels shows that activity is profit led: an exogenous increase of the labor share leads to a reduction in either output gap or employment rate. The effect is slightly more persistent for the employment rate (six quarters) than the output gap (four quarters). Further, the implications is that activity adjusts relatively fast.

To further illustrate, we also apply the "reverse ordering," which implies that activity $\left(u_{t}\right.$, or $e_{t}$ ) has a contemporaneous effect on the labor share $\left(\psi_{t}\right)$, but not vice versa. Results are presented in Figure 4. As before, the top row of panels summarizes output gap and labor share interaction, and the bottom row analogously for the employment rate. The right column of panels suggests that the effect of a distributive shock on activity is insignificant, although there is marginal significance for the employment rate: the confidence intervals for VAR IRFs are negative in the second quarter, and the error bands for LPs are negative in second and third quarter. Still, these responses are very different than the right two panels of Figure 3. 
However, the left two panels indicate that a strong profit squeeze is detected even when this ordering is used. Crucially, the labor share responds significantly and negatively to either activity shock, but "overshoots" after one to two quarters. It then remains significantly elevated for almost the entire period shown on this panel. We intentionally write that $\psi$ overshoots - since the IRFs in the left column are very similar to results presented in Ríos-Rull and Santaeulàlia-Llopis (2010, Fig. 1, p. 934), see also p. 14 above. Their result, "countercyclical on impact, but overshooting," and other related research, builds on new-Keynesian and RBC theory. According to these theories, productivity shocks are critical drivers of the business cycle, and thus are causally prior to other variables. Though that line of research focuses on TFP or productivity shocks, the ordering is conceptually similar (see also discussion regarding Cauvel, 2020, above).

We can briefly summarize as follows. The standard ordering, based on classical and Keynesian theory, confirms the distributive cycle with a strong profit squeeze and profit led activity. The reverse ordering clearly confirms the profit squeeze. Either ordering shows that the labor share has strong persistence following a shock to activity. The weight of the evidence across these subsections - survey, wavelet coherence and phase difference, and vector autoregressions - is strong. The distributive cycle for the US post-war period at business cycle frequency is very robustly detected based on a variety of methods.

\section{Discussion}

Here we provide context and discussion. We focus on two major issues: the incorporation of a financial cycle, and connection to the theme of secular stagnation. Implicit in Keynes's General Theory is the contention that the inclusion of monetary factors changes everything: a monetary theory of production is fundamentally different. Our view is that monetary factors are implicit in Goodwinian frameworks with endogenous aggregate demand, since the financial system (relatively) elastically supplies the funds that drive an expansion. In Section 5.1 we investigate this issue in a three dimensional VAR model in $u, \psi$ and Tobin's $q$, and show that the distributive cycle is robust to the inclusion of the latter. This is particularly relevant in light of some recent research, which suggests the theoretical possibility that the empirically observed Goodwin cycle could exist even with wage led demand (see Stockhammer and Michell, 2017). Our results below show that this theoretical possibility has no support in the data, and hence that Goodwin cycles are real, rather than "pseudo" (ibid.).

Section 5.2 connects the distributive cycle to debates about secular stagnation. The link arises at the steady state: if labor productivity growth rises in the labor share, as in theories of induced technical change (Tavani and Zamparelli, 2020a), higher in-

equality can boost short run accumulation while at the same time depressing steady 
state growth. The simple dichotomy of the debates thus should be resolved: the issue is not about whether short run demand is wage led or profit led; the preceding discussion summarizes in our view conclusively that this issue is settled. The debate should be about how to reconcile short run incentives for policy makers to boost accumulation with the long run necessity of supporting the labor share. It needs to be high enough to allow for the long run reproducibility of labor power, high enough for the long run sustainability of consumption demand, and high enough to provide incentives for labor-saving technical change. In a similar vein, the much-discussed retreat of the state, particularly in terms of the reliance on private provision of research and development and general infrastructure, can erode long run potential.

\subsection{A distributive cycle with financial extension}

The entire preceding discussion has been focused on the real side of the macroeconomy. Given the recent argument that the Goodwin cycle could in theory manifest even with wage led demand (see Stockhammer and Michell, 2017), we now augment the distributive cycle by a financial variable. We find strong empirical evidence for activity to be profit led also in this case. ${ }^{31}$ The area encompasses much of macroeconomics, but we will seek to be very concise.

First, this is not a new idea. Building on Skott (1989), Ryoo (2010) demonstrates how real and financial cycles can interact. A key result is a distributive cycle in $e, \psi$, overlaid with long Minskyan waves (see Fig. 8, p. 180). Similarly, Chiarella and Flaschel (2000); Proaño et al. (2006); Asada et al. (2006); Flaschel (2009) all build on Goodwinian narratives to formulate what they call "matured disequilibrium" models of the macroeconomy. Across these contributions, the profit squeeze mechanism is consistent with monetary factors included in the model. For example (and as discussed already in Section 4.1), Proaño et al. (2006) estimate the US to feature a distributive cycle conditional on the inclusion of a monetary policy rule (see also Flaschel, 2009, Chapter 9). Similarly, Rezai (2013) provides evidence in this vein.

Foley (1987) and Taylor (2012, Section 6) discuss real-financial cycles, but abstract from the price-distributive system. The former constructs a model in three variables: the money-capital ratio, the financial asset-capital ratio, and the profit rate. Since the distribution of income is assumed invariant, the profit rate plays the role of the activity variable, and strong accelerator effects in capital outlays introduce a non-linearity. The author demonstrates that a limit cycle is likely to arise, "because a rise in capital outlays and sales raises the profit rate, which tends to increase borrowing and the rate of expansion" (ibid., p. 374). Outlays, however, are constrained by aggregate liquidity, so that the system is globally stable. The key issue

\footnotetext{
${ }^{31}$ A referee pointed out to us that Minsky's classification of a firm as hedge, speculative, and Ponzi implies the importance of profits for its financial position, and in turn investment plans. Both profit squeeze and profit led (short run) activity could thus be seen as implicit in Minskyan theory; Stockhammer and Michell (2017) include only the former.
} 
(for our purposes) is that the theory underlying the model-with or without the non-linearity - implies a clockwise cycle in activity, here proxied by the profit rate, and aggregate liquidity, here described by the sum of money and financial assets relative to the physical capital stock. In other words, finance leads activity.

Taylor (2012, Section 6), in contrast, uses the accumulation rate as the activity variable, and juxtaposes it with Tobin's $q$. The author also assumes an instability, but focuses on positive own-feedback of asset prices. Specifically, $q$ is unstable, but the (linear) model retains stability through the interaction of the two variables: the negative effect of accumulation on $q$ is sufficient to break the expansion induced by high (and unstable) asset prices. ${ }^{32}$ The critical issue (for our purposes) is that the model predicts a clockwise cycle in activity, here proxied by the accumulation rate, and "finance," here described by Tobin's $q$. In other words, finance leads activity.

With this to set the stage, we propose a simple test of the hypothesis that the distributive cycle - with profit led activity and profit squeeze distribution - is robust to the inclusion of financial factors. As already mentioned, this is relevant since Stockhammer and Michell (2017) have suggested the theoretical possibility that the observed distributive cycle might be "pseudo," in the sense that it is not driven by profit led activity, but instead a profit squeeze and a Minskyan financial link, and possibly compatible even with (weakly) wage led demand. Our discussion here refutes this view; it does not fit the data. Specifically, we can extend the model(s) already utilized in Section 4.3 by a financial variable. The IRFs resulting from such a model provide clear evidence regarding the strength and robustness of the mechanisms underlying the distributive cycle. To foreshadow results, the IRFs do not change: both profit squeeze distribution and profit led activity are apparent when the financial variable is included, and as long as the standard ordering is applied.

This makes intuitive sense. For illustration, consider a two-dimensional differential equation system. For this system to have complex roots (i.e., feature a negative discriminant), the off-diagonal items in the Jacobian matrix must have opposite signs. If two time series portray significant cyclical comovement, a theoretical model with oppositely signed off-diagonal items will fit it better than one without. It follows therefrom that a profit squeeze - undeniable across all literatures and data approaches - should be matched with profit led activity. The latter is clearly detected only in the standard ordering (see Sections 4.1 and 4.3), and the focus on cyclical growth and disequilibrium phenomena in classical-Keynesian research makes this the logical choice.

\footnotetext{
${ }^{32}$ In particular, the Jacobian matrix evaluated at the steady state of the two dimensional differential equations system features a negative trace and a positive determinant, which here implies that the $q$-nullcline is steeper than the $g$-nullcline; see Figure 7, p. 56 . Note also that the columns in Table 3, p 55, are switched: the positive signs should be in the $q$-column.
} 


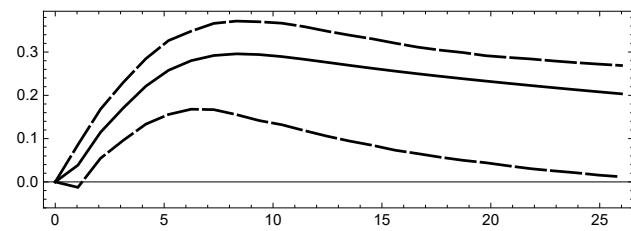

(a) Response of $\psi$ to $u$ shock

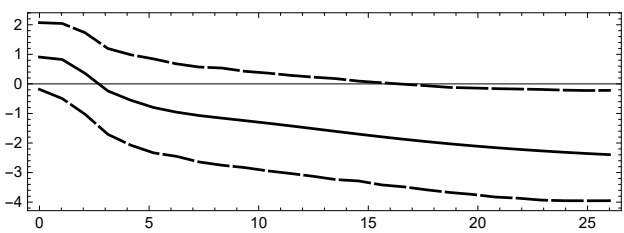

(c) Response of $q$ to $u$ shock

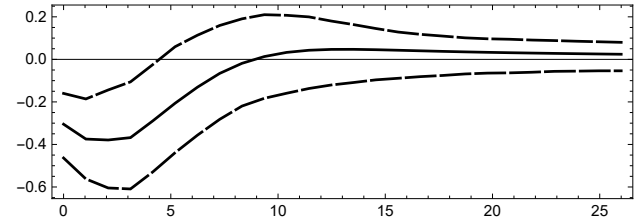

(b) Response of $u$ to $\psi$ shock

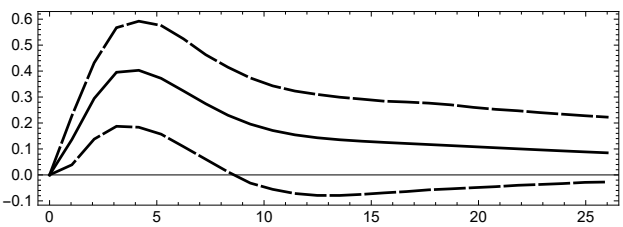

(d) Response of $u$ to $q$ shock

Figure 5: IRFs from 3D VAR including $q$. The panels show IRFs from a three variable recursive VAR in $\psi, u, q$. The ordering of the Cholesky decomposition is $\psi \longrightarrow u \longrightarrow q$. Dashed lines are 95\% confidence intervals. Horizontal axis shows quarters ahead in all figures. Top row is $u, \psi$-interaction, bottom $u, q$. We report neither responses of variables to their own shocks, nor $q, \psi$-interaction. See Section 5.1 for discussion.

In summary, the following VAR results inclusive of a financial cycle strengthen, rather than weaken, evidence for the distributive cycle. Specifically, we employ the output gap as activity variable, and pair it with our labor share measure $\psi_{2}^{g r}$ (see Sections 3 and 4.3) in the standard ordering: the labor share is assumed to be causally prior to macroeconomic activity. Further, we extend the model by Tobin's $q$, and assume it to be causally posterior to both other variables; i.e. $q$, determined in financial markets, is the fastest variable. ${ }^{33}$ The choice of financial variable is not immediately obvious. Interest rates, and especially interest spreads would be consistent with Minskyan theory. Other stock variables (debt, net worth, etc.) are conceivable. We utilize this readily available measure of average $q$ as a bridge between various Keynesian literatures. ${ }^{34}$. In summary, the ordering is $\psi \longrightarrow u \longrightarrow q$, where $\psi, u$ are labor share and output gap as defined above.

Results are presented in Figure 5. The left panels illustrate the responses of labor share and Tobin's $q$ to an output gap shock; right panels the response of the output

\footnotetext{
${ }^{33} \mathrm{~A}$ measure of $q$ is available from FRED, series code is NCBCEPNW. Our sample covers the US post-war period from 1952Q1-2020Q1.

${ }^{34}$ For example, Foley (1987) builds on Minsky, and focuses on the profit rate-interest rate differential; Taylor (2012) on $q$. The latter is the ratio of market valuation - driven by profit expectationsrelative to replacement costs - driven by interest costs; and has been applied across virtually all macro literatures to questions regarding monetary growth. Taylor (2012) also considers a model with household debt, and residential real estate prices. Figure 8 (p. 59) in that paper demonstrates that these variables evolve on a different-much slower-time scale. However, the focus of our investigation here is that of a financial variable that interacts with activity and distribution at business cycle frequency, making $q$ the right choice.
} 
gap to the other two variables. As is clear from these pictures, both profit squeeze distribution and profit led activity are significant even when a financial cycle is included. Further, the direction of both cycles is in line with theory outlined above: PL and PS define the counter-clockwise distributive cycle in $u, \psi$, and output gap and Tobin's $q$ a clockwise cycle in $u, q .{ }^{35}$

We restate our conclusion that the Goodwin cycle is robust to the inclusion of financial variables. The weight of the evidence is considerable, and questions about the short run appear largely settled. The following section discusses why the real beef concerns the long run.

\subsection{Technical change \& secular stagnation}

This section provides a brief overview of recent theoretical work on the distributive cycle. The focus lies on the characteristics of the steady state: if labor productivity growth is increasing in the labor share, the natural growth rate becomes endogenous to the distribution of income. Hence, any model that generates a Goodwin pattern features a trade off between short and long run policy targets: labor suppression can boost short run performance, since it is "profit-led," but could adversely affect long run growth if the (policy) shock becomes permanent and depresses the labor share in steady state. ${ }^{36}$

An important shortcoming of the original Goodwin setup is the assumption of exogenous, purely labor-augmenting technical change. The literature has considered the implications of both the so-called direction of technical change - i.e. the relative weight of capital- vs. labor-augmenting innovation - and the intensity of technical progress - the amount of resources spent on R\&D by profit-seeking capitalists. The former strand of literature, building on seminal contributions by Kennedy (1964) and Drandakis and Phelps (1965), pertains to the effect of induced technical change on the growth cycle; the latter, which draws from mainstream endogenous growth theory à la Romer (1990), regards the role of endogenous technical change.

\footnotetext{
${ }^{35}$ These results are robust to various modifications, for example when the employment rate is used as activity variable and when data is entered in first differences. Further, the reverse ordering between activity and labor share, i.e. $u \longrightarrow \psi \longrightarrow q$, features results very similar to those shown in Figure 4: the profit squeeze is apparent, after a short-lived negative impact, and the effect of a distributive shock on output gap is insignificant. Additionally, usual information criteria show that the optimal lag length should be between 1 and 2 (BIC and AIC, respectively). IRFs however are not sensitive to the lag length parameter. Therefore, the VAR underlying IRFs in Figure 5 employ a lag length of 2. Typical portmanteau tests show no autocorrelation for the residuals. Details are available upon request.

${ }^{36}$ The distinction between temporary and permanent shocks for this discussion is quite critical. Suppose the economy is in steady state. Any temporary shock will then displace it, and trigger a Goodwin-style dynamic movement to return to the initial steady state. A permanent shock triggers the same qualitative dynamic, with convergence to (or around) a new steady state. Careful distinction between the two is not made often enough.
} 
Once augmented by either induced or endogenous technical progress, the Goodwin model delivers a set of important long-run implications connecting the distributive cycle to secular stagnation. We use a stripped down version of the models developed in Shah and Desai (1981); Foley (2003); Julius (2005) with the assumptions made in Section 2 to convey the main points. However, we generalize the model to include a propensity to save out of profits $s_{\pi} \in(0,1]$ to analyze the effects of changes in this parameter in what follows. Let growth rates of labor-augmenting and capital-augmenting technical change be endogenous to income shares as follows: $a=a(\psi), a_{\psi}>0, \dot{\sigma} / \sigma \equiv \chi(\psi)$ such that $\chi(0)>0, \chi_{\psi}<0$. The Goodwin model modifies as follows:

$$
\begin{aligned}
\dot{e} & =e\left(\chi(\psi)+s_{\pi}(1-\psi) \sigma-(a(\psi)+n)\right) \\
\dot{\psi} & =\psi\left(\rho e-\left(\omega_{0}+a(\psi)\right)\right) \\
\dot{\sigma} & =\chi(\psi) \sigma .
\end{aligned}
$$

By ensuring that the long-run income-capital ratio remains constant in steady state, equation (5.3) pins down the long-run labor share as the solution to $\chi\left(\psi_{s s}\right)=0$. Two points are worth making about the long-run solution for income distribution in this model. First, Petach and Tavani (2020) have argued that this solution is compatible with both a merely technological and an institutional explanation of the long-run determination of income shares. Second, in this model the long-run wage share is unrelated to the saving propensity $s_{\pi}$ and, with savings-driven investment, therefore independent of investment behavior.

Next, importantly, evaluating equation (5.2) at a steady state gives the following upward sloping nullcline relating the activity variable - that is, employment - to income distribution:

$$
e(\psi)=\frac{a(\psi)+\omega_{0}}{\rho}
$$

Finally, and equally importantly, the steady state solution for equation (5.1) delivers again an upward sloping nullcline relating the income-capital ratio to the labor share:

$$
\sigma_{s s}=\frac{a(\psi)+n}{s_{\pi}(1-\psi)}
$$

This very simple model can be used to build a classical-Keynesian narrative on the political economy of secular stagnation.

- A technologically or institutionally driven decline in the labor share increases the rate of accumulation $g$, but depresses the long run growth rate of labor productivity $a$ : since the two are inextricably linked in the long run via the balanced growth condition $g=a+n$, the eventual outcome is a decline in the long-run growth rate, even though capital accumulation did initially rise. 
- Moreover, the long-run employment rate - which is tied up to labor productivity growth via equation (5.4) - will decline as well.

- Finally, the fall in the labor share will depress the income-capital ratio (increase the capital-income ratio) in the long run. The falling labor share puts pressure on the accumulation rate: but as the economy moves to its new long run position, restoring the equality between the accumulation rate $g$ and the Harrod rate $a+n$ can only be achieved through a decline (increase) in the long-run income-capital (capital-income) ratio.

It is worth noting that this narrative stands in contrast with the famous argument by Piketty (2013), in which a rate of return to capital $r$ greater than the growth rate $g$ determines an increase in the capital-income ratio $1 / \sigma$, and a decline in the labor share via an elasticity of substitution in production higher than one. The above explanation starts with the distributional changes, and does not require high substitution elasticity given that the underlying production technology is Leontief.

While the argument above has natural appeal, it is not immune to criticism, especially because the long-run income distribution is de facto exogenous. Tavani and Zamparelli (2020b) have focused on endogenous, purely labor-augmenting technical change financed out of capitalist profits. The model delivers again a direct dependence of labor productivity growth on the wage share, but boils down to two equations, as the dynamic behavior of the income-capital ratio is now absent:

$$
\begin{aligned}
\dot{e} & =e\left(s_{\pi}(1-\psi) \sigma-\left(a\left(\psi ; s_{\pi}\right)+n\right)\right) \\
\dot{\psi} & =\psi\left(\rho e-\left(\omega_{0}+a\left(\psi ; s_{\pi}\right)\right)\right)
\end{aligned}
$$

The steady state is described by equation (5.4) and the implicit solution to:

$$
1-\psi_{s s}=\frac{a\left(\psi_{s s} ; s_{\pi}\right)+n}{s_{\pi} \sigma}
$$

In this framework, Tavani and Zamparelli (2020b) thus show that the long-run wage share is directly related to the saving rate out of profits $s_{\pi}$, which contrasts with the induced technical change model. Given that long-run employment is wage-led as above, an increase in the saving rate puts upward pressure on both accumulation and labor-saving R\&D spending. The former effect is stronger, and employment rises: real wages must follow given the real wage Phillips curve. The ultimate effect is that of an increase in the wage share in the long run. A key aspect of this model is that it provides a link to a demand-driven explanation of growth, distribution, and cyclical dynamics, through its focus on the determinants of investment. Straightforward extensions that include independent investment functions can be put together, although that tends to come at a cost of abandoning microeconomic foundations. ${ }^{37}$

\footnotetext{
${ }^{37}$ For recent discussions along these lines, see Barrales et al. (2021) and Rada and von Arnim (2021).
} 
Further, an alternative scenario considers the role of public R\&D as well as infrastructure spending on the distributive cycle. This highlights explicit policy channels, and in that manner provides an even closer link to demand policy by focusing on the share of public spending in GDP, G/Y. Specifically, Tavani and Zamparelli (2020a) have argued that an increase in the share of infrastructure spending (financed out of a tax on profits) always increases the wage share in the long-run, thus lending support to longstanding arguments concerning linkages between inequality, growth and demand policy. Still, the trade-off between private and public capital accumulation is mediated through the distribution of income: the steady-state wage share is hump-shaped in the share of government spending (on public R\&D and public capital) in GDP, and there exists a labor-share maximizing $G / Y$ ratio. Back-of-theenvelope calculations for the US led Tavani and Zamparelli (2020a) to conclude that the country could substantially reduce inequality by raising public spending, even at a balanced budget.

In summary, the relevant research agenda is to tease out the positive long run association between activity and labor share via both supply and demand-side policy variables, conditional on the Goodwin pattern at business cycle frequency. ${ }^{38}$ The latter is central for such an agenda, since the profit squeeze mechanism provides the foundation for real wages to catch up to productivity advances, and in turn lays the foundation for the next round of innovations.

\section{Conclusion}

This paper outlines theoretical motivations for a distributive cycle, provides summary and udpates of evidence in favor of it, refutes recent criticism in regard to a financial cycle, and explains why the distributive cycle is a very useful entry point for debates about secular stagnation. In conclusion, the Goodwin model, in its various incarnations and with various extensions, rightfully retains its place as the workhorse model of classical-Keynesian macroeconomics.

In these concluding paragraphs, we emphasize what this paper has not done. For starters, the survey is not comprehensive. We largely disregard important literatures, for example on separate wage and price Phillips curves. But even within the more narrow literature on trend and cycles of the labor share we have neglected important topics. These include research (i) on the sources of labor share changes at the sector and firm level, (ii) on product market concentration and the resulting pricing power of firms, (iii) secular trends in globalization and financialization, and (iv) the forces of the lower turning point in the distributive cycle.

The trend decline of the labor share since (roughly) 1980, and then its precipitous collapse since (roughly) 2000, has triggered a burgeoning literature on sectoral and

\footnotetext{
${ }^{38}$ See also footnote 17 and long run measurement and empirical issues touched upon on p. 21.
} 
firm level issues. Elsby et al. (2013) is an important early paper; Autor et al. (2017); Kehrig and Vincent (2020); Mendieta-Muñoz et al. (2020); Taylor and Ömer (2020) are recent examples. Key insights are that the trend decline of the labor share is driven from within sectors, but occurs across firms: first, the majority of sectors experience labor share declines, and reallocation effects buffer the aggregate decline since sectors with higher labor shares experience employment growth; but, second, the largest and most productive firms have been able to increase market shares, and also have the lowest labor shares. Reallocation of value added across firms therefore plays a role in the decline.

In all of this, the manufacturing sector and structural changes engulfing it are a key part. For our purposes here, it is particularly relevant that the cyclical fluctuations of the aggregate labor share appear to be driven to a large extent by this one sector. Mendieta-Muñoz et al. (2020, Fig. A3) report year-to-year contributions by sectors to the aggregate labor share change, based on a Divisia index decomposition. The volatility of manufacturing's contribution vastly exceeds that of other sectors, but also has decreased in recent decades as its employment share has significantly declined. In frameworks with induced (or endogenous) technical change, a direct implication is that such a weakening of the cyclical profit squeeze due to structural change can lead to a decline of the natural rate of growth. For recent contributions in this vein, see Schiavone et al. (2021); Barrales et al. (2021).

Autor et al. (2017) and de Loecker et al. (2020) connect firm level data to questions of market power. These studies clearly demonstrate that increasing concentration in product markets correlates with lower labor shares and higher mark-ups. Importantly, both papers find that changes are driven by the tails of the firm distribution: the largest firms with smallest labor shares attain ever larger market shares; and mark-ups increase most strongly for firms that already have the highest mark-ups. ${ }^{39}$ Further research could clarify if and how these trend changes affect the distributive cycle, and how the increase in firms' pricing power in product markets relates to the decrease of labor's bargaining power in labor markets.

Further, to keep this paper within reasonable length, we have not discussed trends of globalization and financialization. We will here only very briefly touch on key issues. First, Blecker (1989, p. 407) outlined the possibility of a fallacy of composition in multi-country contexts when net exports rise with competitiveness and are an important source of demand. While theoretical contributions in this vein have been made, it is empirically still underresearched. Exceptions are Blecker and Razmi (2008), Kiefer and Rada (2015) and Rada and Kiefer (2016). Especially the latter two papers directly tie the distributive cycle to a "race-to-the-bottom." This appears to be a fruitful way to go about it (see Skott, 2017, for a related methodological

\footnotetext{
${ }^{39}$ de Loecker et al. (2020) show that the median mark-up remains largely unchanged; Kehrig and Vincent (2020) show that the median manufacturing firm (by value added) experienced an increase in the labor share. Much-discussed trends clearly have important micro-level features.
} 
discussion). Drawing on multi-country panels in this context can potentially relax some data limitations regarding long run issues.

Financialization - a trend that is distinct from the financial cycle considered in Section 5.1 - represents a similar conundrum, and recent research has sought to connect it to the decline in the labor share and broader macroeconomic performance (Hein, 2013; Dünhaupt, 2017; Pariboni and Tridico, 2019). This line of research does not usually build on the distributive cycle - where financialization could either weaken or strengthen accumulation, depending on whether it is understood to ease financing constraints, or divert funds from productive investment. Time-varying parameter estimates could seek to identify such linkages. The apparent weakening of the mechanisms underlying the distributive cycle is an important and unresolved topic.

Importantly, supply-driven versions of the distributive cycle have no demand problems. Further work could seek to identify to what extent aggregate demand expectations or specific expenditure components (residential investment, etc.) contribute to the initial upturn. In short, if the income-capital ratio is constant, a falling labor share is sufficient to lead to an upswing; if it is not and persistently depressed, the labor share could fall to zero and the upswing still would not occur.

Further research on all these matters can continue to advance our understanding.

\section{Bibliography}

Aguiar-Conraria, L. and Soares, M. (2014). "Continuous wavelet transform, economic fluctuations, multiple wavelet coherency, partial wavelet coherency, wavelet coherency, wavelet partial phase-difference," Journal of Economic Surveys, 28(2): 344-375.

Akerlof, G.A. and Stiglitz, J.E. (1968) "Capital, wages and structural unemployment," The Economic Journal, 79:314, 269-281.

Alvaredo, F., Chancel, L., Piketty, T., Saez, E., and Zucman, G. (2018). The elephant curve of global inequality and growth. American Economic Review: Papers and Proceedings, 108:103-108.

Asada, T., Chen, P., Chiarella, C. and Peter Flaschel (2006), "Keynesian dynamics and the wage-price spiral. A baseline disequilibrium model," Journal of Macroeconomics, 28:90130 .

Autor, D., Dorn, D., Katz, L., Patterson, C., and Van Reenen, J. (2017). "Concentrating on the fall of the labor share," American Economic Review, 107(5):180-185.

Basu, D. and Foley, D.K. (2013). "Dynamics of output and employment in the US economy," Cambridge Journal of Economics, 37(5):1077-1106.

Barbosa, N. and Taylor, L (2006). "Distributive and demand cycles in the US economy: A structuralist Goodwin model," Metroeconomica, 57(3): 389-411. 
Barkai, S. (2020). "Declining labor and capital shares," Journal of Finance, https://doi.org/10.1111/jofi.12909.

Barrales, J.; Mendieta-Muñoz, I.; Rada, C.; Schiavone, A. and von Arnim, R. (forthcoming), "The post-war trajectory of the US labor share: Structural change and secular stagnation," in Stiglitz, J.E. and von Arnim, R. (eds.), The Great Polarization: Economics, Institutions and Policies in the Age of Inequality, New York, NY: Columbia University Press.

Barrales, J. and von Arnim, R. (2017). "Longer-run distributive cycles: Wavelet decompositions for the US, 1948-2011," Review of Keynesian Economics, 5(2):196-217.

Barrales, J. and von Arnim, R. (2020). "Endogenous fluctuations in demand and distribution: An empirical investigation," mimeo.

Basu, D., and Gautham, L. (2019). "What is the impact of an exogenous shock to the wage share? VAR results for the US economy, 1973-2018," UMASS Amherst Economics Working Papers, No. 2019-08.

Blecker, R. (1989) "International competition, income distribution and economic growth," Cambridge Journal of Economics, 13:395-412.

Blecker, R. (2016). "Wage-led versus profit-led demand regimes: the long and the short of it," Review of Keynesian Economics, 4(4):373-390.

Blecker, R. and Razmi, A. (2019). "The fallacy of composition and contractionary devaluations: output effects of real exchange rate shocks in semi-industrialized countries," Cambridge Journal of Economics, 32:83-109.

Blecker, R. and Setterfield, M. (2019). Heterodox macroeconomics: Models of demand, distribution and growth. Northampton, MA: Edward Elgar.

Blecker, R., Cauvel, M. and Kim, Y. (2020). "Systems estimation of a structural model of distribution and demand in the US economy," mimeo.

Bridgman, B. (2018). "Is labor's loss capital's gain? Gross versus net labor shares," Macroeconomic Dynamics, 22:2070-2087.

Brooks, C. (2019). Introductory Econometrics for Finance, Cambridge: Cambridge University Press. 4th edt.

Cauvel, M. (2020). "The neo-Goodwinian model reconsidered," mimeo.

Carvalho, L. and Rezai, A. (2016) "Personal income inequality and aggregate demand," Cambridge Journal of Economics, 40(2):491-505.

Charpe, M., Bridji, S. and McAdam, P. (2019). "Labor share and growth in the long run," Macroeconomic Dynamics, 1-38, doi:10.1017/S1365100518001025.

Christiano, L.J., Eichenbaum, M. and Evans, C.L. (1999) "Monetary policy shocks: What have we learned and to what end?" Handbook of macroeconomics, 1(1999):65-148.

Chiarella, C. and Flaschel, P. (2000). The dynamics of Keynesian monetary growth: Macrofoundations. Cambridge, UK: Cambridge University Press. 
Chirinko, R.S., and Mallick, D. (2017). "The substitution elasticity, factor shares, and the low-frequency panel model," American Economic Journal: Macroeconomics, 9(4): 225253.

Colciago, A. and Rossi, L. (2015). "Firm dynamics, endogenous markups and the labor share of income," Macroeconomic Dynamics, 19:1309-1331

Comin, D. and Gertler, M. (2006). "Medium-term business cycles," American Economic Review, 96(3):523-551.

Desai, M., Henry, B., Mosley, A. and Pemberton, M. (2006). "A clarification of the Goodwin model of the growth cycle," Journal of Economic Dynamics and Control, 30:2661-2670.

de Loecker, J., Eeckhout, J. and Unger, G. (2020) "The rise of market power and the macroeconomic implications," The Quarterly Journal of Economics, 135(2):561-644.

Drandakis, E.M. and Phelps, E.S. (1965) "A model of induced invention, growth and distribution," Economic Journal 76(304): 823-840.

Duménil, G. and Lévy, D. (2015). Neoliberal managerial capitalism. International Journal of Political Economy, 44(3):71-89.

Dünhaupt, P. (2017). "Determinants of labor's income share in the era of financialisation," Cambridge Journal of Economics, 41(1): 283-306.

Elsby, M. W., Hobijn, B., and Şahin, A. (2013). "The decline of the US labor share," Brookings Papers on Economic Activity, 44(2): 1-63.

Enders. W. (2015). Applied Econometric Time Series. New York: Wiley, 4th edt.

Flaschel, P. (1993). Macrodynamics: Income Distribution, effective demand and cyclical growth. Frankfurt a.M.: Peter Lang.

Flaschel, P. (2009). The macrodynamics of capitalism: Elements for a synthesis of Marx, Keynes and Schumpeter. Berlin: Springer.

Flaschel, P. (2015). "Goodwin's MKS system: A baseline macro model," Cambridge Journal of Economics, 39(3): 1591-1605.

Flaschel, P. and Krolzig, H.M. (2006). "Wage-price Phillips curves and macroeconomic stability: Basic structural form, estimation and analysis." In Chiarella, C., Flaschel, P., Franke, R. and Semmler, W. (eds). Quantitative and empirical analysis of nonlinear $d y$ namic macromodels. Cambridge: Harvard University Press, pp. 7-47.

Foley, D., and Michl, T. (1999). Growth and Distribution, Harvard University press, Cambridge, MA.

Foley, D. (1987). "Liquidity-profit rate cycles in a capitalist economy," Journal of Economic Behavior and Organization, 8:363-376.

Foley, D. (2003). "Endogenous technical change with externalities in a classical growth model," Journal of Economic Behavior and Organization, 52(2):167-89. 
Franke, R. and Asada, T. (1994). "A Keynes-Goodwin model of the business cycle". Journal of Economic Behavior and Organization, 24:273-295.

Freitas, F. and Serrano, F. (2015) "Growth rate and level effects, the stability of the adjustment of capacity to demand and the Sraffian supermultiplier," Review of Political Economy, 27(3):258-281.

Gallegati, Marco; Gallegati, Mauro; Ramsey, J.B. and Semmler, W. (2011) "The US wage Phillips curve across frequencies and over time," Oxford Bulletin of Economics and Statistics, 73(4):489-508.

Gandolfo, G. (2010). Economic Dynamics New York, NY: Springer.

Gollin, D. (2002). "Getting income shares right," The Journal of Political Economy, $110(2): 458-474$.

Gomme, P. and Rupert, P. (2004). "Measuring labor's share of income," Federal Reserve Bank of Cleveland Policy Discussion Paper, No. 7, Nov. 2004.

Gomme, P. and Rupert, P. (2007). "Theory, measurement and calibration of macroeconomic models," Journal of Monetary Economics, 54:460-497.

Goodwin, R.M. (1939). "The nonlinear accelerator and the persistence of business cycles," Econometrica, 19(1):1-17.

Goodwin, R.M. (1967), "A growth cycle," in C.H. Feinstein (ed.), Socialism, Capitalism and Growth: Essays Presented to Maurice Dobb, Cambridge, UK: Cambridge University Press, pp. 54-58.

Goodwin, R.M. (1989). Essays in Nonlinear Economic Dynamics, Bern, Peter Lang.

Growiec, J., McAdam, P. and Mućk, J. (2018) "Endogenous labor share cycles: Theory and evidence," Journal of Economic Dynamics and Control, 87: 74-93

Harrod, R.F. (1939) "An essay in dynamic theory". The Economic Journal, 49(193): 14-33.

Hein, E. (2013). "Finance-dominated capitalism and redistribution of income: a Kaleckian perspective". Cambridge Journal of Economics, 39(3): 907-934.

Jordà, Ò. (2005). "Estimation and inference of impulse responses by local projections". American Economic Review, 95: 161-182.

Julius, A.J. (2005). "Steady-state growth and distribution with an endogenous direction of technical change". Metroeconomica, 56(1):101-125

Kehrig, M. and Vincent, N. (2020) "The micro-level anatomy of the labor share decline," NBER Working Paper No. 25275.

Kiefer, D. and Rada, C. (2015) "Profit maximising goes global: The race to the bottom," Cambridge Journal of Economics 39(5):1333-1350.

Kiefer, D. Mendieta-Muñoz, I., Rada, C. and von Arnim, R. (2020) "Secular stagnation and income distribution dynamics," Review of Radical Political Economics 52(2):189-207. 
Kennedy, C. (1964). "Induced bias in innovation and the theory of distribution," Economic Journal 74(295), 541-547.

Koh, D.; Santaeulàlia-Llopis, R. and Zheng, Y. (2020) "Labor share decline and intellectual property products capital," Econometrica, https://doi.org/10.3982/ECTA17477.

Lavoie, M. (2017). "The origins and evolution of the debate on wage-led and profitled regimes," European Journal of Economics and Economic Policies: Intervention, $14(2): 200-221$.

León-Ledesma, M.A., and Satchi, M. (2019) "Appropriate Technology and Balanced Growth," The Review of Economic Studies, 86:807-835

Lorenz, H.-W. (1993). Nonlinear Dynamical Economics and Chaotic Motion New York, NY: Springer.

Lotka, A.Y. (1925). Elements of Physical Biology, Baltimore, MD: Wiliams and Wilkins.

McAdam, P. and Willman, A. (2013) "Medium run redux," Macroeconomic Dynamics, 17(4):695-727.

Mendieta-Muñoz, I., Rada, C., and von Arnim, R. (2020) "The decline of the U.S. labor share across sectors," Review of Income and Wealth, in print, DOI: 10.1111/roiw.12487.

Mendieta-Muñoz, I., Rada, C., Santetti, M. and von Arnim, R. (2020) "The US labor share of income: What shocks matter?" Review of Social Economy, in print, https://doi.org/10.1080/00346764.2020.1821907.

Mohun, S. and R. Veneziani (2006). "Goodwin cycles and the US economy, 1948-2004," MPRA Working Paper, No. 30444.

Mućk, J., McAdam, P. and Growiec, J. (2018) "Will the true labor share stand up? An applied survey on labor share measures," Journal of Economic Surveys, 32(4):961-984.

Nikiforos, M. (2020). "Notes on the accumulation and utilization of capital". Levy Institute Working Paper No. 953.

Nikiforos, M. and Foley, D. (2012). "Distribution and capacity utilization: Conceptual issues and empirical evidence". Metroeconomica, 63(1): 200-229.

Nguyen Huu, A. and Costa-Lima, B. (2014). "Orbits in a stochastic Goodwin-Lotka-Volterra model". Journal of Mathematical Analysis and Applications, 419(1): 48-67.

Pariboni, R., and Tridico, P. (2019). "Labor share decline, financialisation and structural change". Cambridge Journal of Economics, 43(4): 1073-1102.

Petach, L., and Tavani, D. (2020). "Income shares, secular stagnation, and the long-run distribution of wealth." Metroeconomica 71(1): 235-255.

Piketty, T. (2013). Capital in the XXI Century. Belknap.

Piketty, T. and Saez, E. (2003). "Income inequality in the United States, 1913-1998." Quarterly Journal of Economics, 118(1):1-39. 
Proaño, C., Flaschel, P., Ernst, E., and Semmler, W. (2006). "Disequilibrium macroeconomic dynamics, income distribution and wage-price Phillips curves. Evidence from the US and the Euro area," IMK Working Paper, No. 4.

Rada, C. and von Arnim, R. (2021). "Classical and Keynesian vignettes on secular stagnation: From labor suppression to natural growth," presented at Thomas R. Michl Festschrift Sessions, EEA conference, February 2021.

Rada, C., and Kiefer, D. (2016). "Distribution-utilization interactions: A race to the bottom among OECD countries," Metroeconomica, 67(2): 477-498.

Raval, D. (2017). "What's wrong with Capital in the Twenty-First Century's model?". In Boushey, H., DeLong, J.B., and Steinbaum, M. (eds). After Piketty: The Agenda for Economics and Inequality. Cambridge: Harvard University Press, pp. 75-98.

Rezai, A., (2013). "Cycles of demand and distribution and monetary policy in the US economy," Journal of Post-Keynesian Economics, 36, 231-250.

Ríos-Rull, J.-V. and Santaeulàlia-Llopis, R. (2010). "Redistributive shocks and productivity shocks," Journal of Monetary Economics, 57:931-948

Rognlie, M. (2015) "Deciphering the fall and rise in the net capital share: Accumulation or scarcity?" Brookings Papers on Economic Activity, 2:1-54.

Romer, P., (1990). "Endogenous Technological Change," Journal of Political Economy 98(5): S71-S102.

Ryoo, S. (2010) "Long waves and short cycles in a model of endogenous financial fragility," Journal of Economic Behavior and Organization, 74:163-186.

Santos, J.F.C and Araujo, R.A. (2020). "Using non-linear estimation strategies to test an extended version of the Goodwin model on the US economy," Review of Keynesian Economics, 8(2):268-286.

Schiavone, A.; Rada. C. and von Arnim, R. (2021) "Goodwin, Baumol and Lewis: How structural change can lead to stagnation," mimeo.

Shah, A., and Desai, M. (1981) "Growth cycles with induced technical change," Economic Journal, 91(364):1006-10.

Shao, E. and Silos, P. (2014) "Accounting for the cyclical dynamics of income shares," Economic Inquiry, 52:778-795.

Sims, C. (1980). "Macroeconomics and reality," Econometrica, 48: 1-49.

Sims, C.A.; Stock, J.H. and Watson, M.W. (1990). "Inference in linear time series models with some unit roots," Econometrica, 58(1): 113-114.

Skott, P. (1989) "Effective demand, class struggle and cyclical growth," International Economic Review, 30(1):231-247.

Skott, Peter. (2017) "Weaknesses of 'wage-led growth'," Review of Keynesian Economics, $5(3): 336-359$. 
Solow, R.M. (1990). "Goodwin's growth cycle: Reminiscence and rumination". In Velupillai, K. (ed). Nonlinear and multisectoral macrodynamics: Essays in honor of Richard Goodwin. New York, NY: New York University Press, pp. 31-42.

Stockhammer, E. and Michell, J. (2017) "Pseudo-Goodwin cycles in a Minsky model," Cambridge Journal of Economics, 41:105-125.

Stockhammer, E. and Onaran, Ö. (2004) "Accumulation, distribution and employment: A structural VAR approach to a Kaleckian macro model," 15(4):421-447.

Taylor, L., and Ömer, Ö. (2020). "Where do profits and jobs come from? Employment and distribution in the US economy". Review of Social Economy, 78(1): 98-117.

Taylor, L. (2004). Reconstructing macroeconomics: Structuralist Proposals and Critiques of the Mainstream, Cambridge, MA: Harvard University Press.

Taylor, L. (2012). "Growth, cycles, asset prices and finance," Metroeconomica, 63(1):40-63.

Tavani, D.; Flaschel, P. and Taylor, L. (2011). "Estimated non-linearities and multiple equilibria in a model of distributive-demand cycles," International Review of Applied Economics, 25(5):519-38

Tavani, D. (2012). "Wage bargaining and induced technical change in a linear economy: Model and application to the US (1963-2003)," Structural Change and Economic Dynamics, 23(2):117-26.

Tavani, D. and Zamparelli, L. (2015). "Endogenous technical change, employment and distribution in the Goodwin model of the growth cycle," Studies in Nonlinear Dynamics and Econometrics, 19(2):209-226.

Tavani, D. and Zamparelli, L. (2017). "Endogenous technical change in alternative theories of growth and distribution," Journal of Economic Surveys, 31(5): 1272-1303.

Tavani, D., and Zamparelli, L., (2020). "Labor-augmenting technical change and the labor share: New microeconomic foundations," available at SSRN: https://ssrn.com/abstract $=3527634$.

van der Ploeg, F. (1987). "Growth cycles, induced technical change, add perpetual conflict over the distribution of income," Journal of Macroeconomics, 9(1):1--12.

Volterra, V. (1931). Leçons sur la Théorie Mathématique de la Lutte pour la Vie, Paris: Gauthier-Villar Notes.

von Arnim, R. and Barrales, J. (2015). "Demand-driven Goodwin cycles with Kaldorian and Kaleckian features," Review of Keynesian Economics, 3(3):351-373.

Young, A.T. (2004) "Labor's share fluctuations, biased technical change, and the business cycle," Review of Economic Dynamics, 7(4):916-931.

Zamparelli, L. (2015). "Induced innovation, endogenous technical change and income distribution in a labor-constrained model of classical growth," Metroeconomica, 66(2):243-262.

Zipperer, B. and Skott, P.(2011). "Cyclical patterns of employment, utilization, and profitability," Journal of Post Keynesian Economics, 34(1):25-57. 


\section{A Continuous Wavelet Transform}

The continuous wavelet transform (CWT) is a transform that maps a time series from its time domain into the time-frequency domain. It provides a suitable way to represent and study the co-movements of time series that evolves in time and frequencies. This appendix heavily draws on Aguiar-Conraria and Soares (2014).

Given the time series $x(t) \in L^{2}(\Re)$, its CWT regarding the mother wavelet $\psi(t)$ is defined as an inner product between $x(t)$ and the family $\psi_{\tau, s}(t)$ of wavelet daughter functions:

$$
W_{x}(\tau, s)=\left\langle x(t), \psi_{\tau, s}(t)\right\rangle=\int_{-\infty}^{+\infty} x(t) \bar{\psi}_{\tau, s}(t) d t
$$

where $\bar{x}$ is the complex conjugate of $x$ and $\psi_{\tau, s}=|s|^{-1 / 2} \psi((t-\tau) / s), \tau, s \in \Re, s \neq 0$. The position of the mother wavelet function in both time and scale is governed by two parameters $\tau$ and $s$, i.e., the translation and scaling parameters, respectively.

The mother wavelet must fulfill two requirements: (1) $\psi(t) \in L^{2}(\Re)$ and (2) the so-called admissibility condition:

$$
0<C_{\psi}=\int_{-\infty}^{+\infty} \frac{|\Psi(\omega)|}{|\omega|}<+\infty
$$

with $|\Psi(\omega)|$ the Fourier transform of the mother wavelet and $\omega$ the angular frequency. The admissibility condition allows the perfect reconstruction of the original time series from the CWT, i.e.,

$$
x(t)=\frac{1}{C_{\psi}} \int_{-\infty}^{+\infty}\left[\int_{-\infty}^{+\infty} W_{x}(\tau, s) \psi_{\tau, s} d \tau\right] \frac{d s}{s^{2}}, \quad s \neq 0 .
$$

Moreover, it preserves energy, i.e.,

$$
\|x\|^{2}=\int_{-\infty}^{+\infty}|x(t)|^{2} d t=\frac{1}{C_{\psi}} \int_{-\infty}^{+\infty}\left[\int_{-\infty}^{+\infty}\left|W_{x}(\tau, s)\right| d \tau\right] \frac{d s}{s^{2}}
$$

\section{A.1 Wavelet power spectrum and wavelet phase}

The local power spectrum for CWT can be written as

$$
(\mathrm{WPS})_{x}(\tau, s)=\left|W_{x}(\tau, s)\right|^{2}
$$

When the wavelet function is complex-valued, the wavelet transform is also complexvalued. Therefore, it can be written as $W_{x}(\tau, s)=\left|W_{x}(\tau, s)\right| e^{i \phi_{x}(\tau, s)}$, with $\left|W_{x}(\tau, s)\right|$ the amplitude and $\phi_{x}(\tau, s)$ the phase.

The phase can be recovered from the CWT as

$$
\phi_{x}(\tau, s)=\arctan \left(\frac{\Im\left\{W_{x}\right\}}{\Re\left\{W_{x}\right\}}\right)^{2}
$$

with $\Im\{x\}$ and $\Re\{x\}$ representing the imaginary and real part of $x$. 


\section{A.2 Cross-wavelet power}

The cross-wavelet power for the time series $x(t)$ and $y(t)$ is defined as

$$
W_{x y}=W_{x} \bar{W}_{y}
$$

where $W_{x}$ and $W_{y}$ are the CWT for $x(t)$ and $y(t)$ respectively. From equation (A.7), the cross-wavelet power can be obtained as

$$
(\mathrm{XWP})_{x y}=\left|W_{x y}\right|
$$

Another important measure of synchrony between $x$ and $y$ is the so-called wavelet coherence that can be defined as the absolute value of the complex coherence,

$$
R_{x y}(\tau, s)=\frac{\left|S\left(W_{x y}\right)\right|}{\left[\left|S\left(W_{x}\right)\right|^{2}\left|S\left(W_{y}\right)\right|^{2}\right]^{1 / 2}}
$$

with $S$ denoting the a smoothing operator in both time and frequency domain. $0<R_{x y}<0$. By writing the complex coherence in polar form, a phase difference can be calculated as

$$
\phi_{x y}(\tau, s)=\arctan \left(\frac{\Im\left\{S\left(W_{x y}\right)\right\}}{\Re\left\{S\left(W_{x y}\right)\right\}}\right)
$$

with $-\pi<\phi_{x y}<\pi$.

Table 1: The lead-lag relationship

\begin{tabular}{cll}
\hline & $x$ leads $y$ & $y$ leads $x$ \\
\hline In-phase & $\phi_{x y} \in(0, \pi / 2)$ & $\phi_{x y} \in(-\pi / 2,0)$ \\
Out-phase & $\phi_{x y} \in(-\pi,-\pi / 2)$ & $\phi_{x y} \in(\pi / 2, \pi)$ \\
Total phase & $\phi_{x y} \in(0, \pi / 2) \cup(-\pi,-\pi / 2)$ & $\phi_{x y} \in(-\pi / 2,0) \cup(\pi / 2, \pi)$ \\
\hline
\end{tabular}

If the phase difference is zero then both series move together at some specific timefrequency, while if the phase difference is $\pi$ both series move in opposite directions. Table 1 shows possible lead-lag relations. If the phase is between $(0, \pi / 2)$ and $(-\pi / 2,0)$ the time series are said to be in-phase, therefore, moving together. However, in the former $x$ leads $y$ (or $y$ lags $x$ ), while in the later $y$ leads $x$ (or $x$ lags $y$ ). On the other hand, if the phase is between $(-\pi,-\pi / 2)$ and $(\pi / 2, \pi)$ the series are said to be out-phase (or anti-phase). In the former, $x$ leads $y$ while in the later $y$ leads $x$. 


\section{B Phase difference of model variants: A Monte Carlo study}

In this appendix we provide illustrative simulations for several models that describe the interaction between activity and distribution. We consider three versions: (1) Goodwin's original model with stochastic labor productivity growth as in Nguyen Huu and Costa-Lima (2013), (2) linearized models as in Barbosa and Taylor (2006), and (3) a variant with a nonlinearity in output growth, where we draw on von Arnim and Barrales (2015). The target is to identify ranges on the vertical axis of Figure 2 for which the Goodwin pattern (counter-clockwise cycle in activity-labor share plane) is observed.

A stochastic version of Goodwin's growth cycle is presented in Nguyen Huu and Costa-Lima (2013) and can be summarized by the following stochastic differential equations:

$$
\begin{aligned}
\dot{\psi} & =\psi\left[\left(\Phi(e)-\alpha+\sigma^{2}(e)\right) d t+\sigma(e) d W\right] \\
\dot{e} & =e\left[\left((1-\psi) / v-\gamma+\sigma^{2}(e)\right) d t+\sigma(e) d W\right]
\end{aligned}
$$

where $\psi, e, \alpha, v$ and $\gamma$ are wage share, employment rate, labor productivity growth, constant capital-output ratio and natural growth rate, respectively. Further, $\Phi(e)=$ $\phi_{0}+\phi_{1} /(1-e)^{2}$ is the Phillips curve. It is assumed that labor productivity grows at a stochastic rate with standard deviation $\sigma(e)=\sigma_{0}(1-e) ; W$ is standard Brownian motion.

The other model variants can be described as follows:

$$
\begin{aligned}
\dot{x} & =\beta\left[h_{x} f(x-\bar{x})+h_{\psi}(\psi-\bar{\psi})\right] d t+\sigma_{0} d W^{x} \\
\dot{\psi} & =\alpha\left[a_{x}(x-\bar{x})+a_{\psi}(\psi-\bar{\psi})\right] d t+\sigma_{0} d W^{\psi}
\end{aligned}
$$

where $x$ represents economic activity and $\alpha, \beta, h_{x}, h_{\psi}, a_{x}, a_{\psi}, \sigma_{0}, \bar{\psi}, \bar{x}$ are parameters. Function $f($.$) defines whether the model is linear, i.e., f(x)=x$, or has a nonlinearity that gives rise to a limit cycle, i.e., $f(x)=\tan ^{-1}(x)$. 


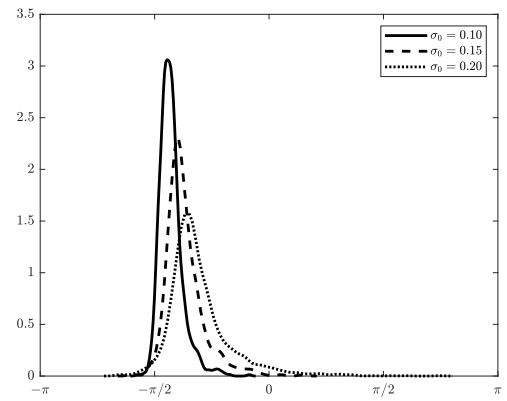

(a) Goodwin 67: IR/CC

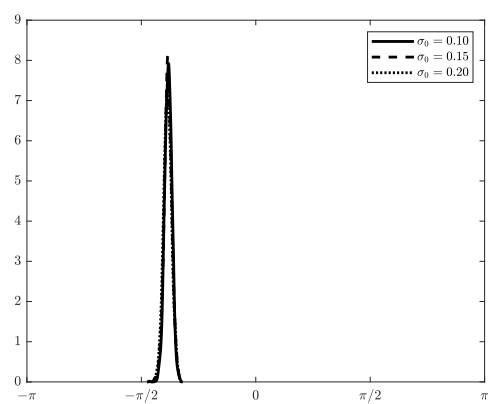

(b) Limit cycle PL/PS: CR/CC

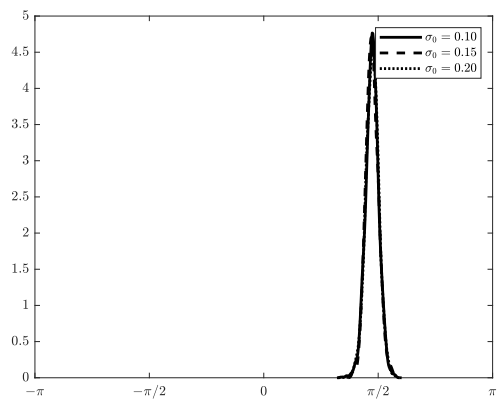

(d) Linear WL/FS: CR/Clockwise

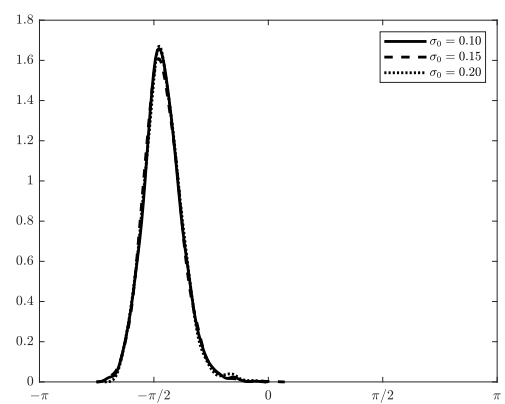

(c) Linear PL/PS: CR/CC

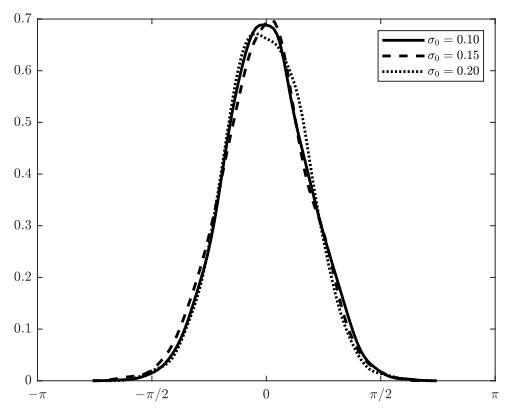

(e) Linear WL/PS: RR/Monotonic

Figure 6: Phase differences: These panels show Monte Carlo simulations for (a) the growth cycle with stochastic labor productivity growth as in Nguyen Huu and Costa-Lima (2013), (b) a limit cycle model as in von Arnim and Barrales (2015), and (c)-(e) three different parameterizations of a linearized model as in Barbosa and Taylor (2006). PL and WL are profit led or wage led activity, respectively; and PS and FS profit squeeze or forced saving distribution. IR, CR and RR are purely imaginary, complex and real roots, respectively; CC stands for the counter-clockwise cycle in activity-labor share plane. Probability distributions represent average phase differences over 2000 samples with size 300. See Section 4.2 for further discussion; further details are available upon request. 